\title{
Command Shaping For Residual Vibration Free
}

\section{Crane Maneuvers}

\begin{abstract}
Cranes used in the construction and transportation industries are generally devices with multiple degrees of freedom including variable load-line length, variable jib length (usually via a trolley), and variable boom angles. Point-to-point payload maneuvers using cranes are performed so as not to excite the spherical pendulum modes of their cable and payload assemblies. Typically, these pendulum modes, although time-varying, exhibit low frequencies. Current crane maneuvers are therefore performed slowly contributing to high construction and transportation costs. This investigation details a general method for applying command shaping to various multiple degree of freedom cranes such that the payload moves to a specified point without residual oscillation. A dynamic programming method is used for general command shaping for optimal maneuvers. Computationally, the dynamic programming approach requires order $M$ calculations to arrive at a solution, where $M$ is the number of discretizations of the input commands. This feature is exploited for the crane command shaping problem allowing for rapid calculation of command histories. Fast generation of commands is a necessity for practical use of command shaping for the applications described in this work. These results are compared to near-optimal solutions where the commands are linear combinations of acceleration pulse basis functions. The pulse shape is required due to hardware requirements. The weights on the basis functions are chosen as the solution to a parameter optimization problem solved using a Recursive Quadratic Programming technique. Simulation results and
\end{abstract}

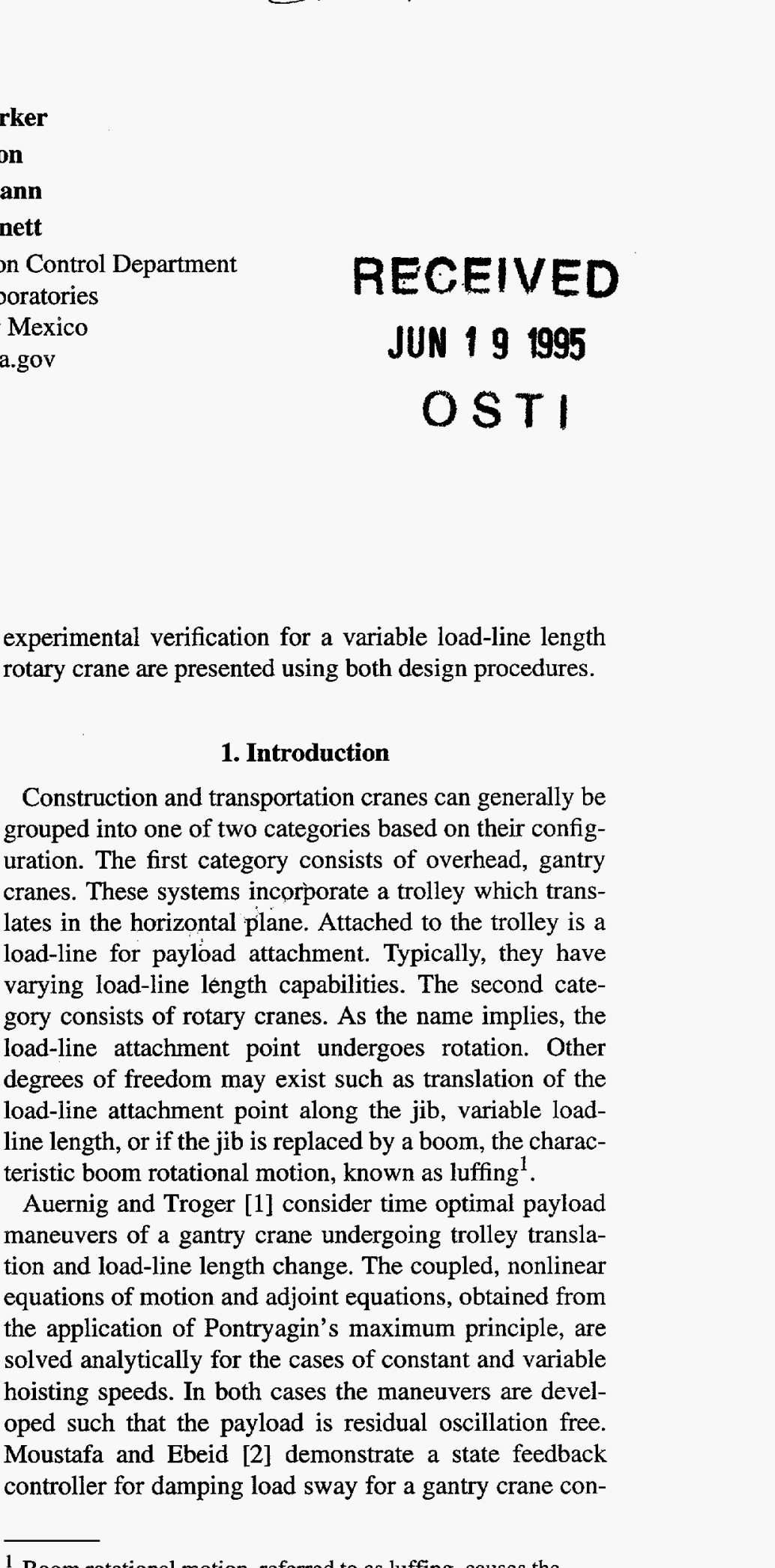

rker
on
ann
nett
on Control Department
onotatories
Mexico
a.gov

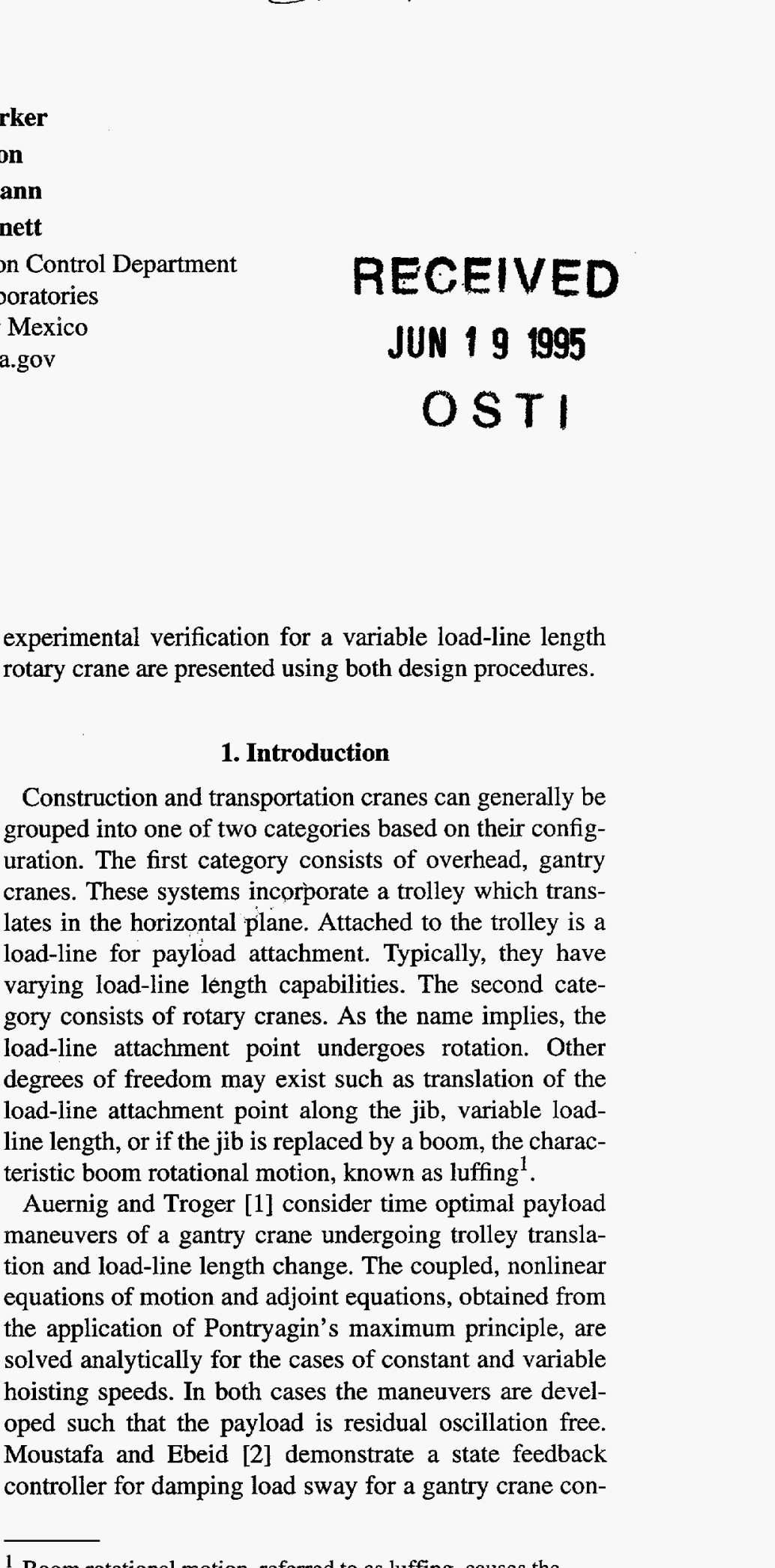

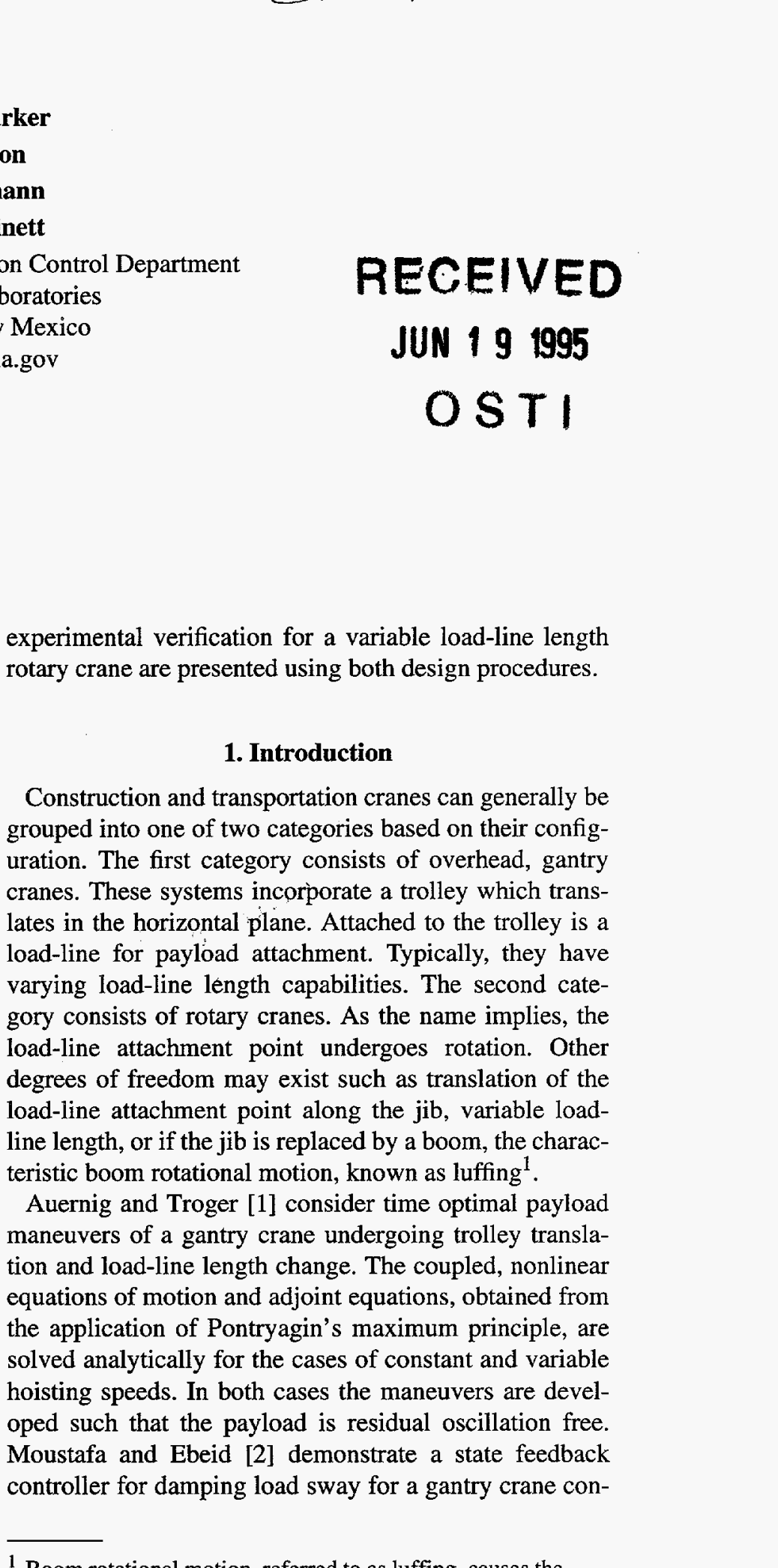

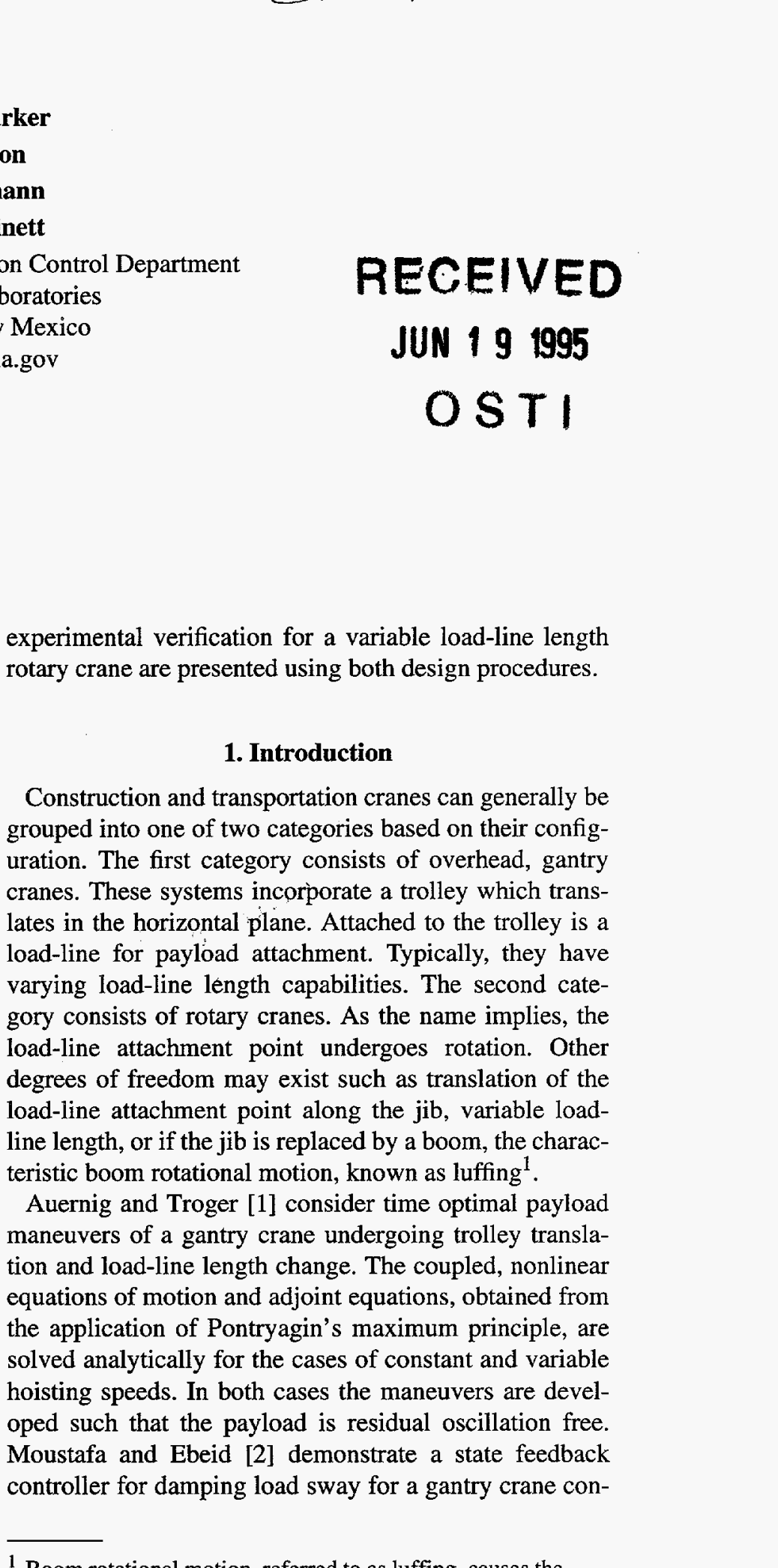

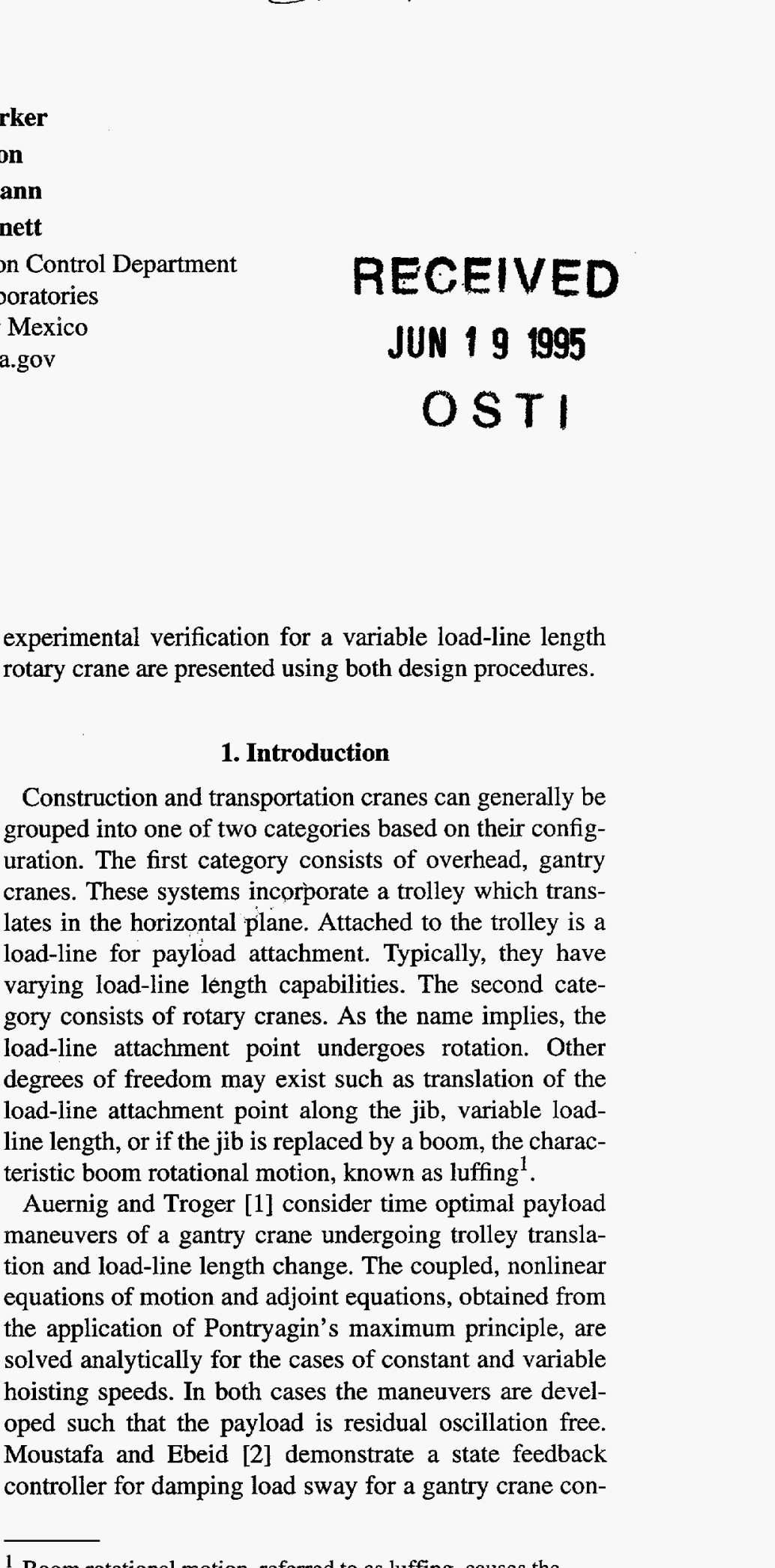

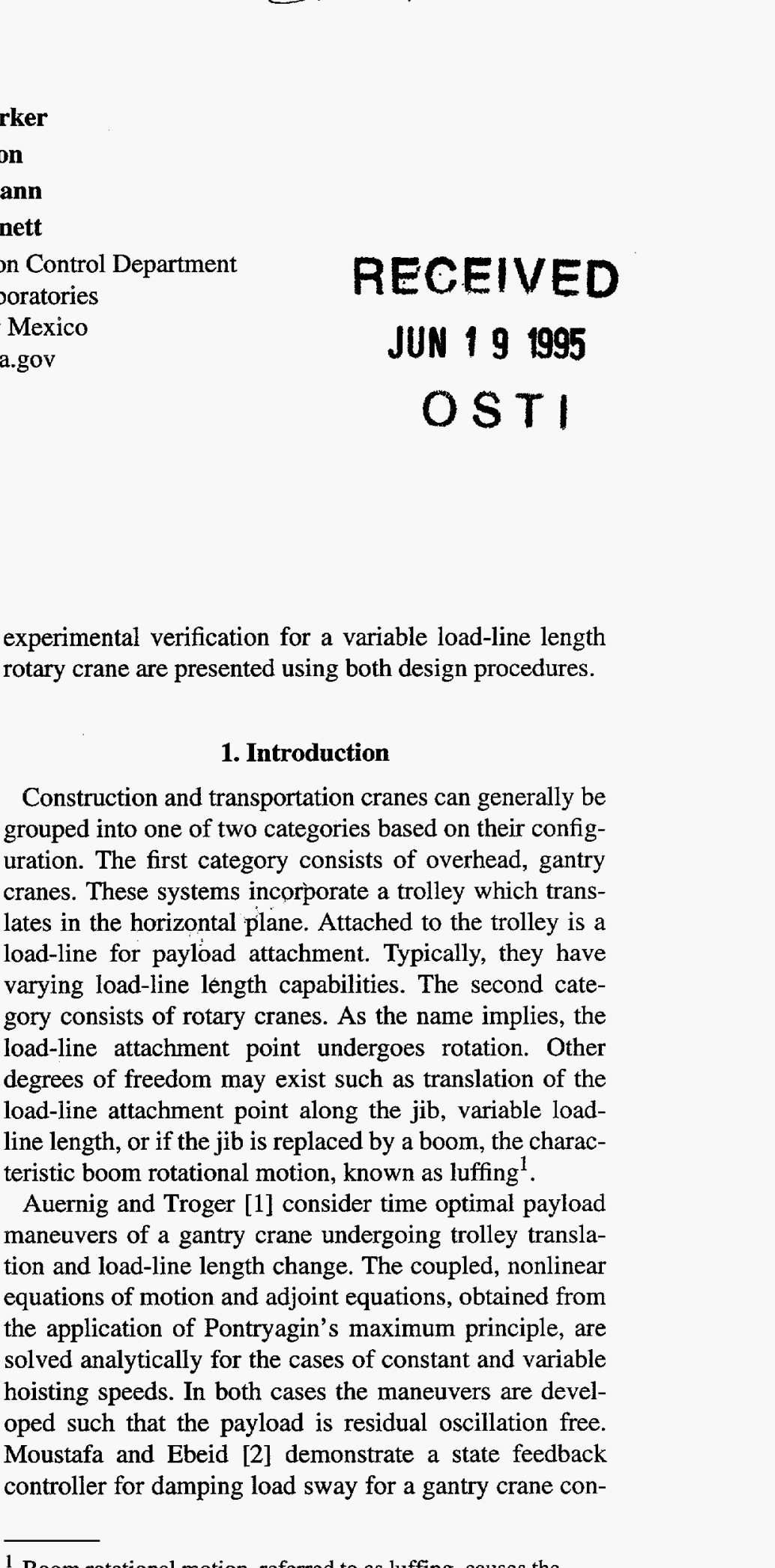

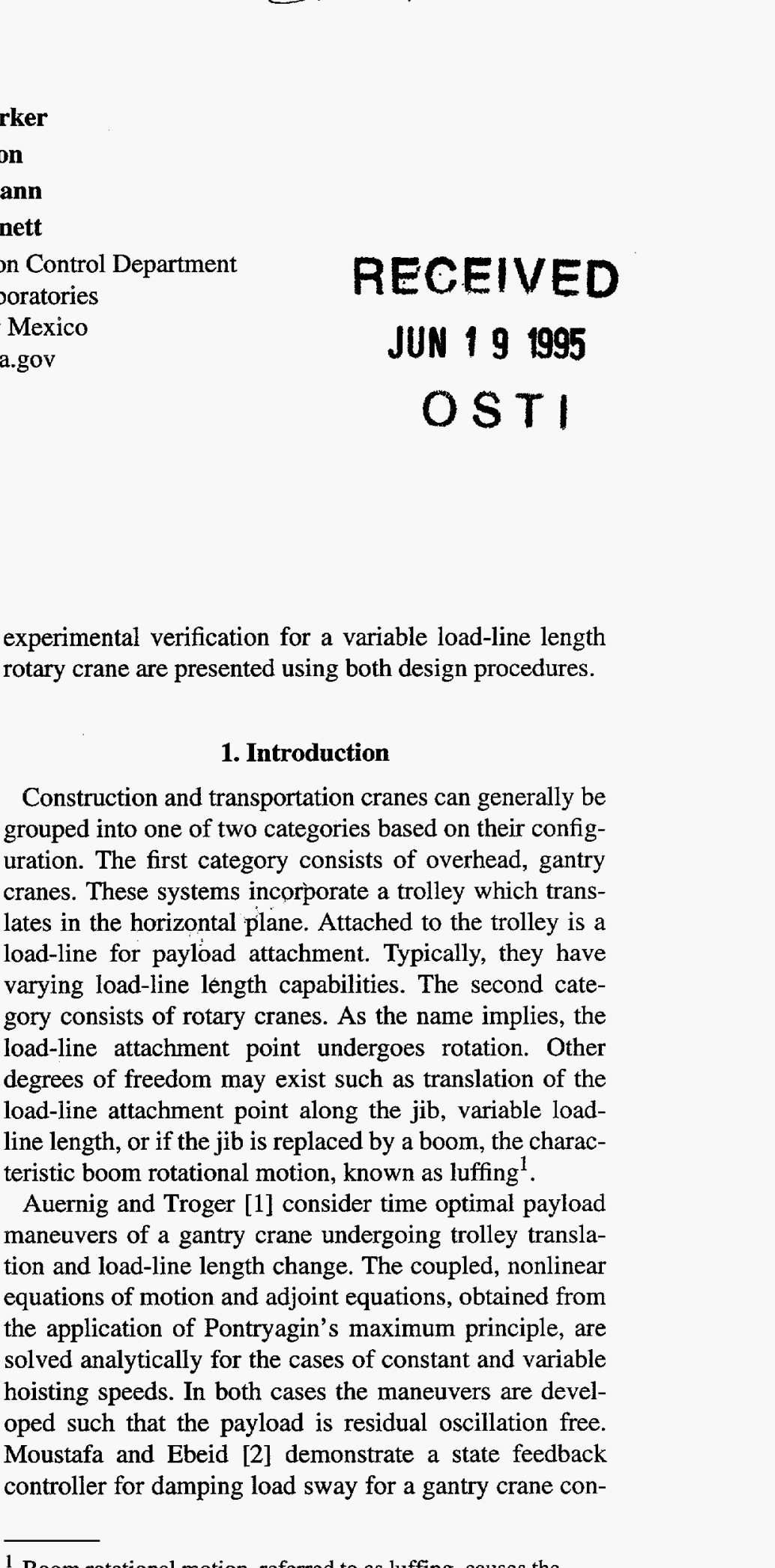

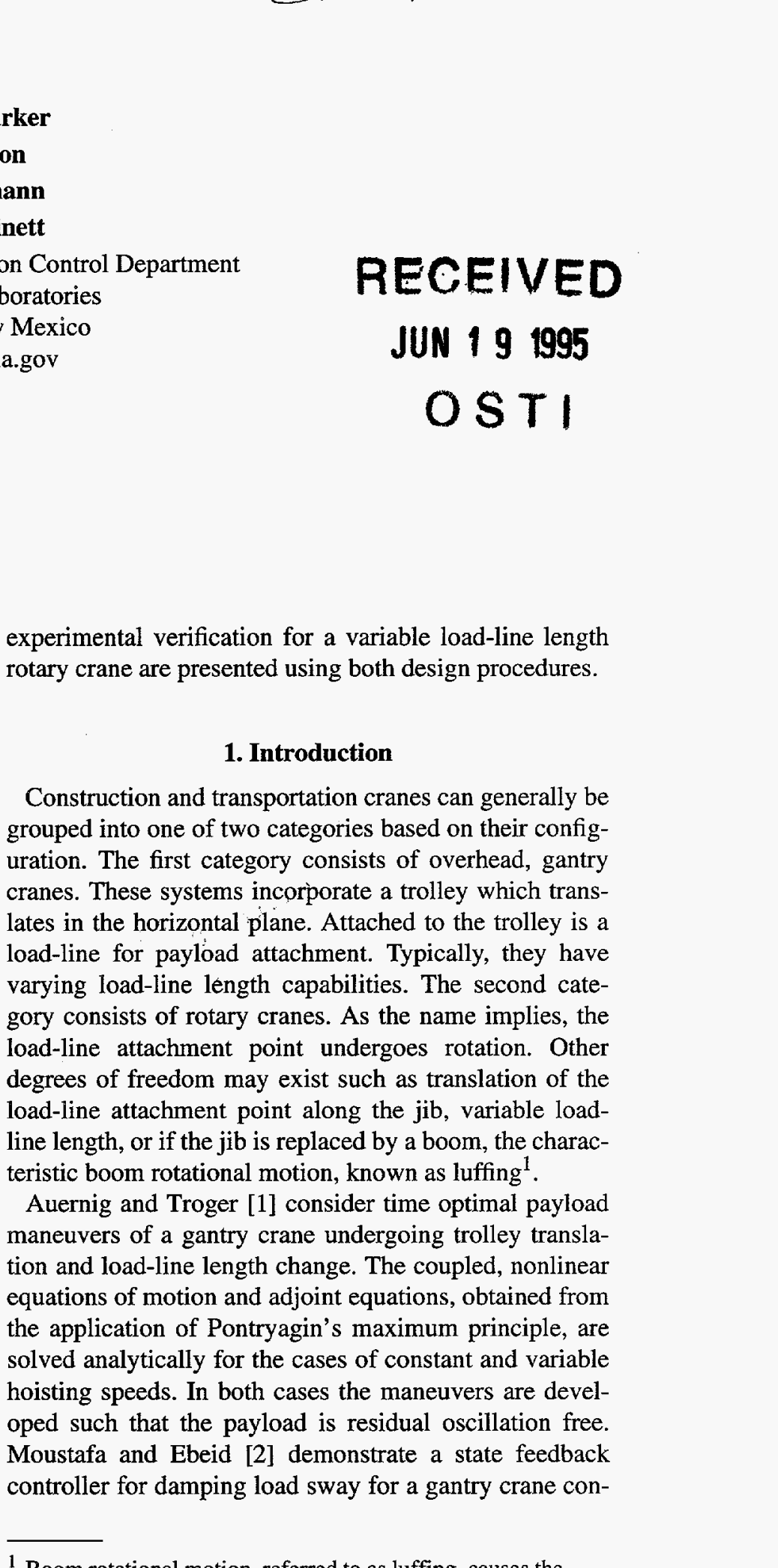

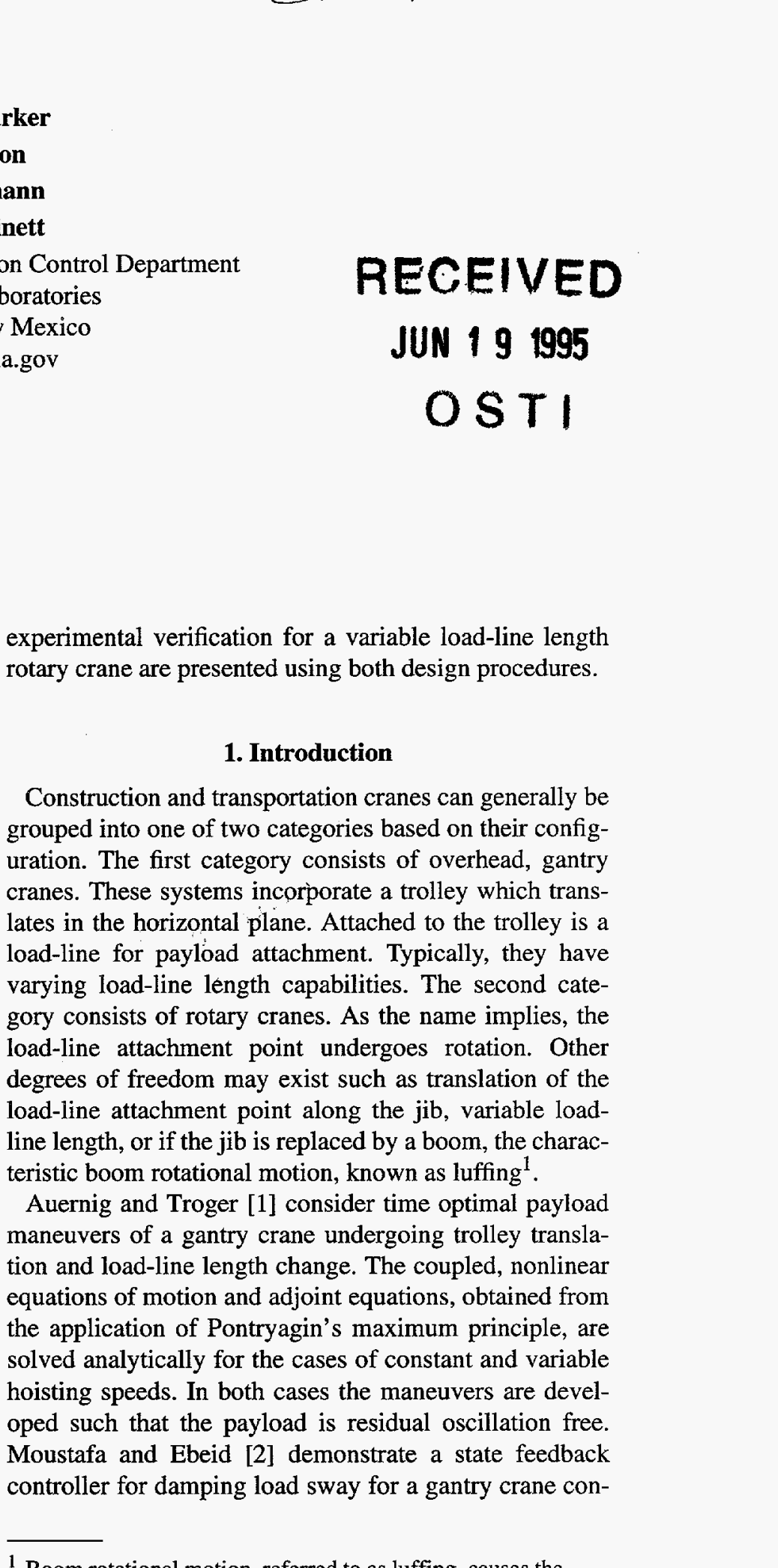

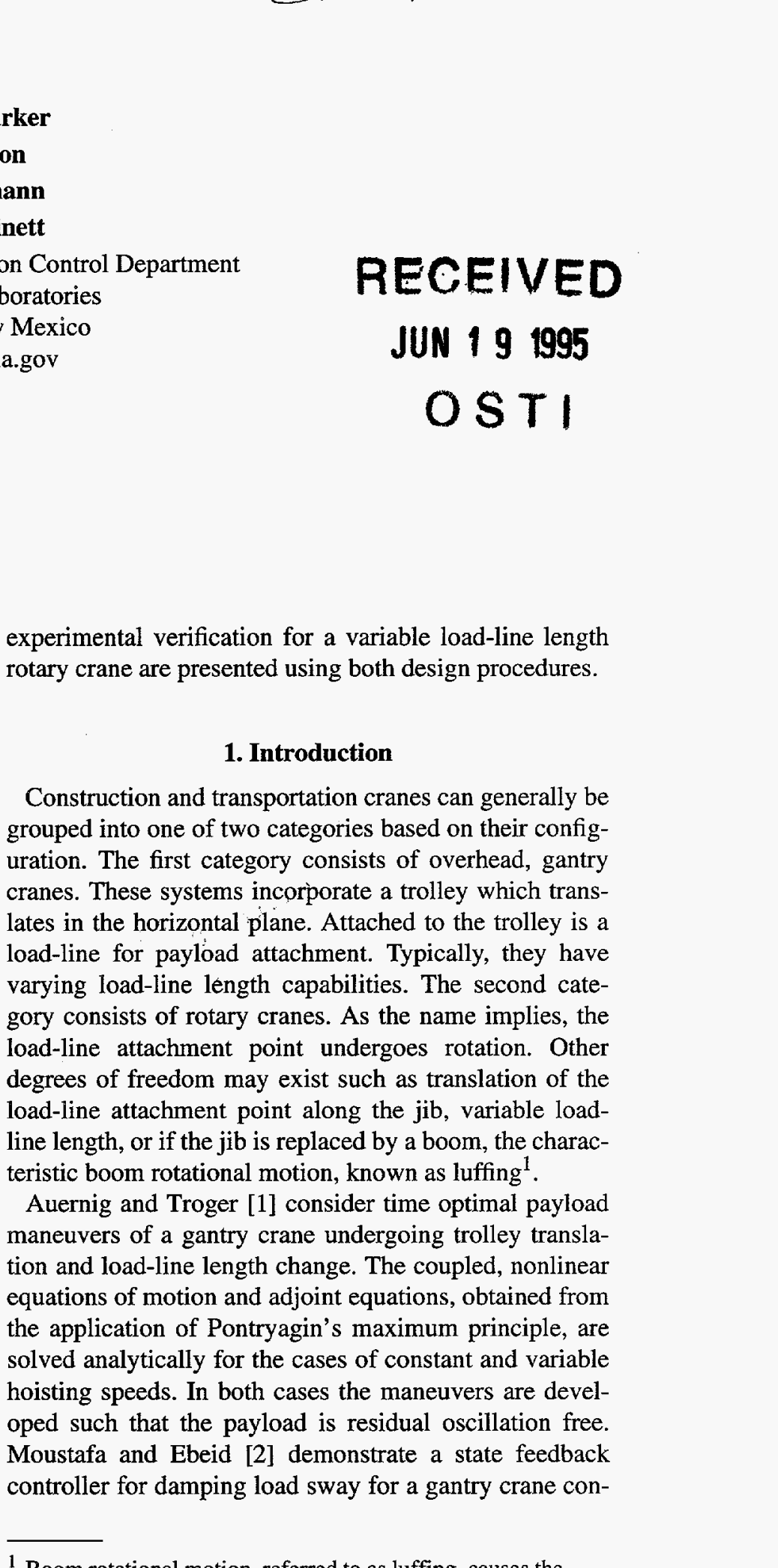

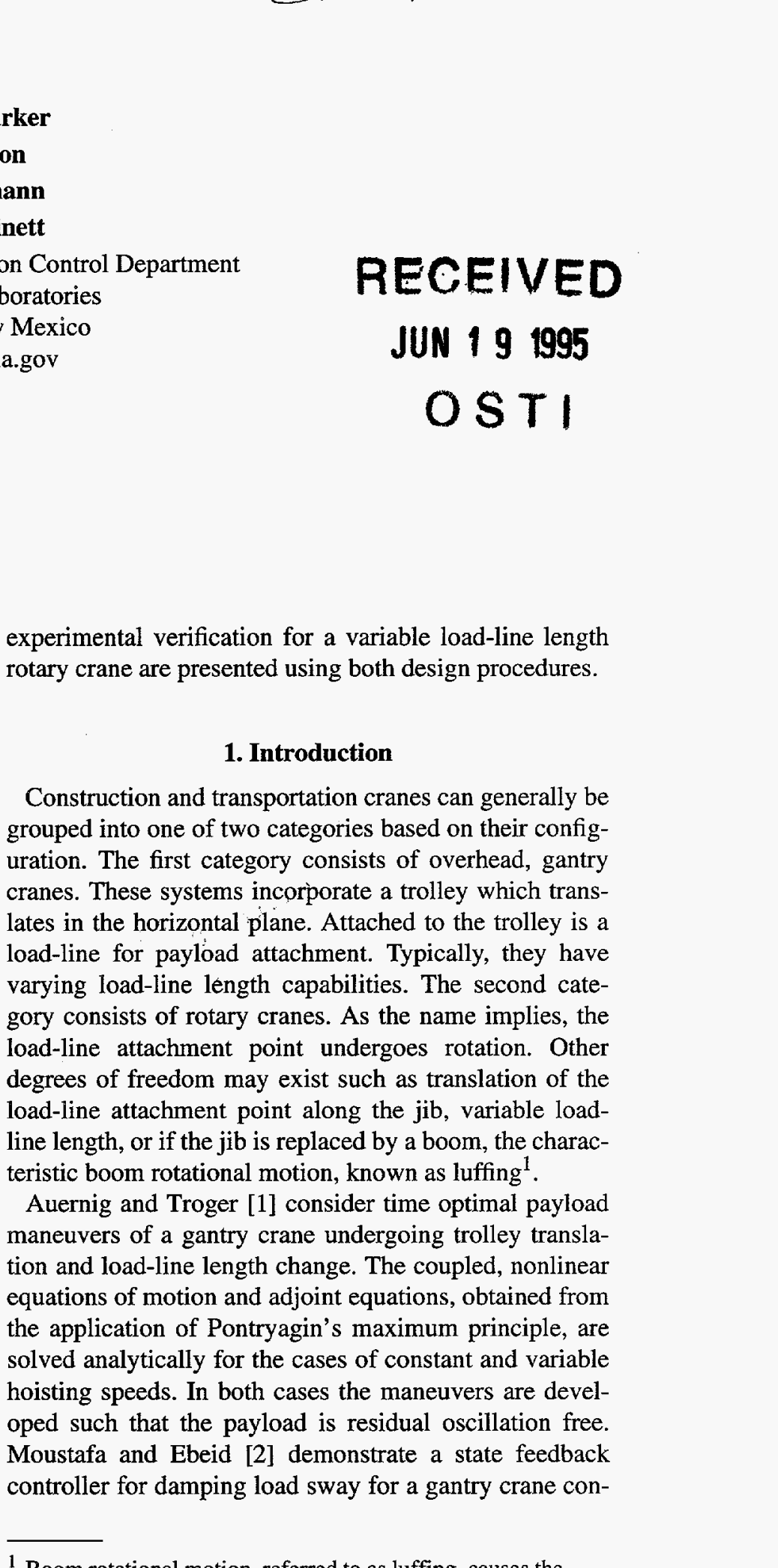

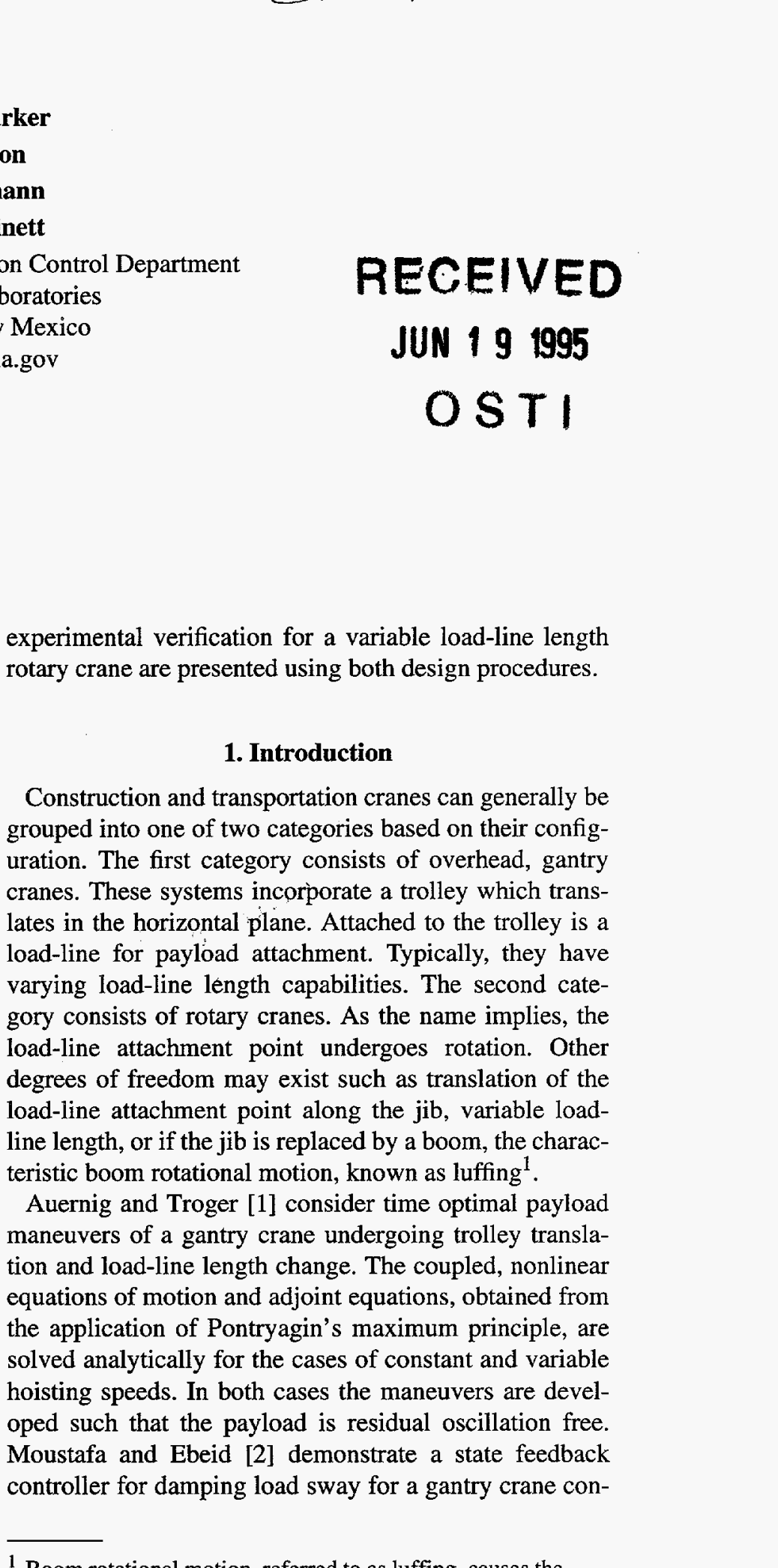

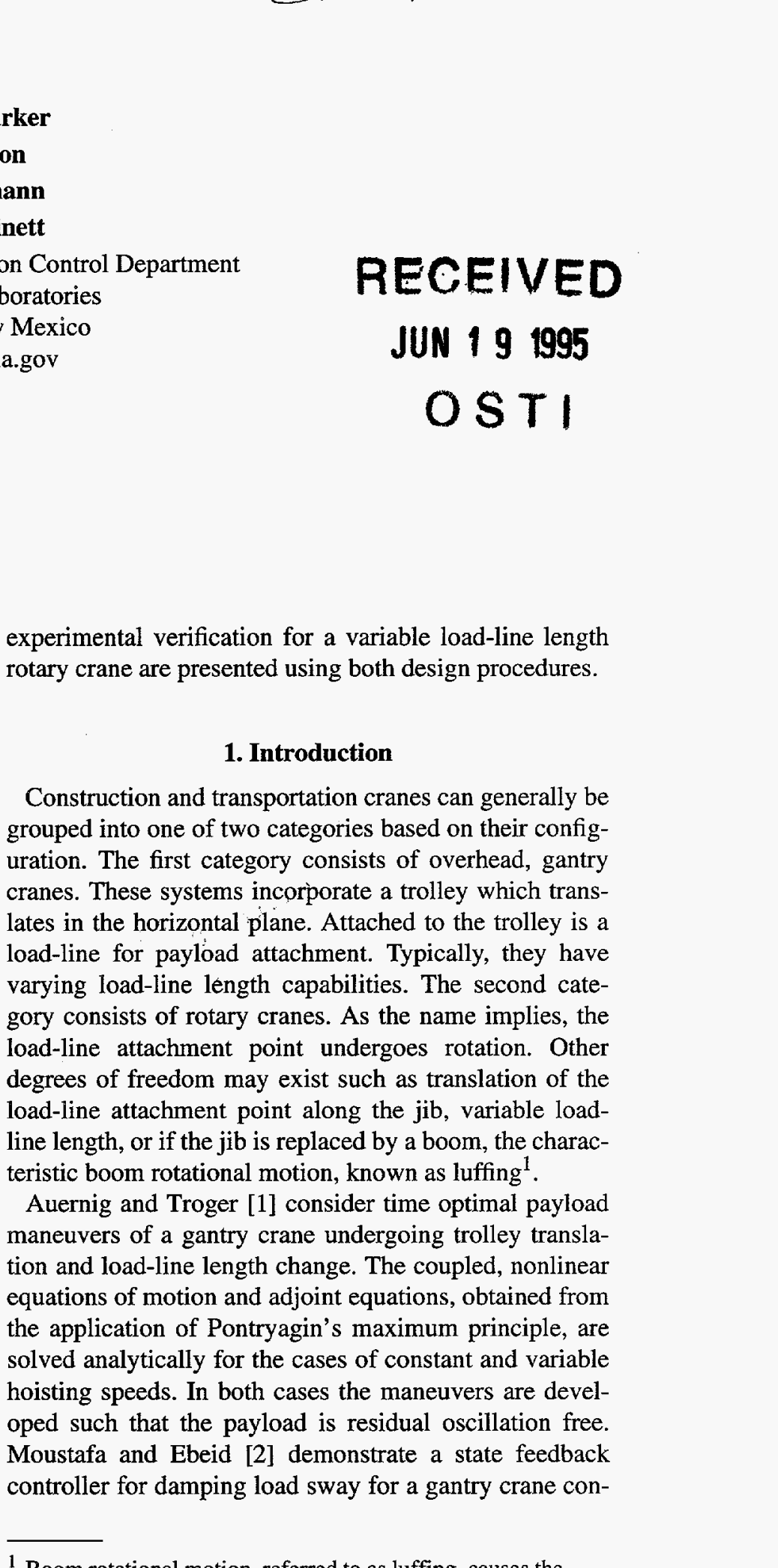

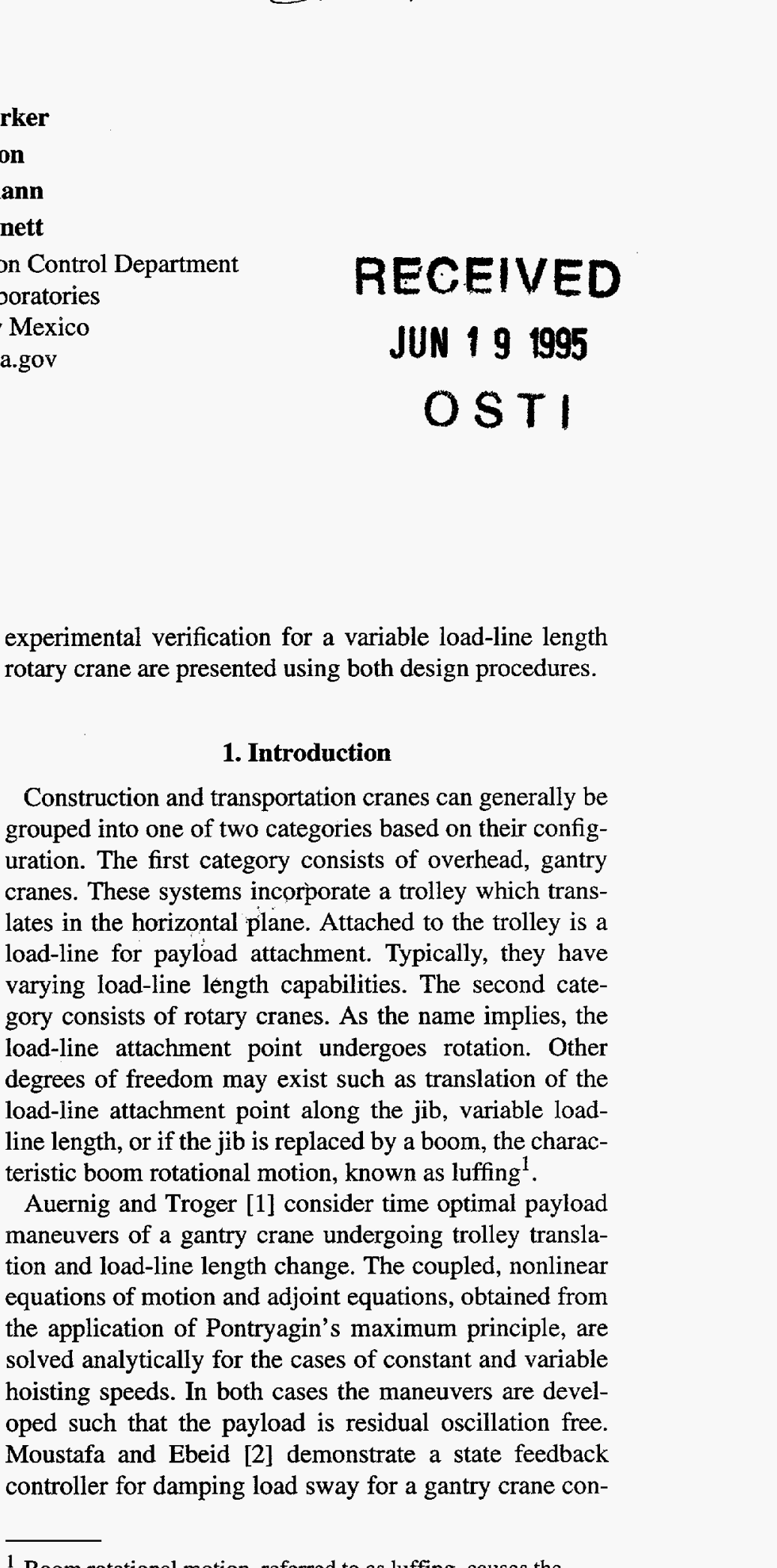

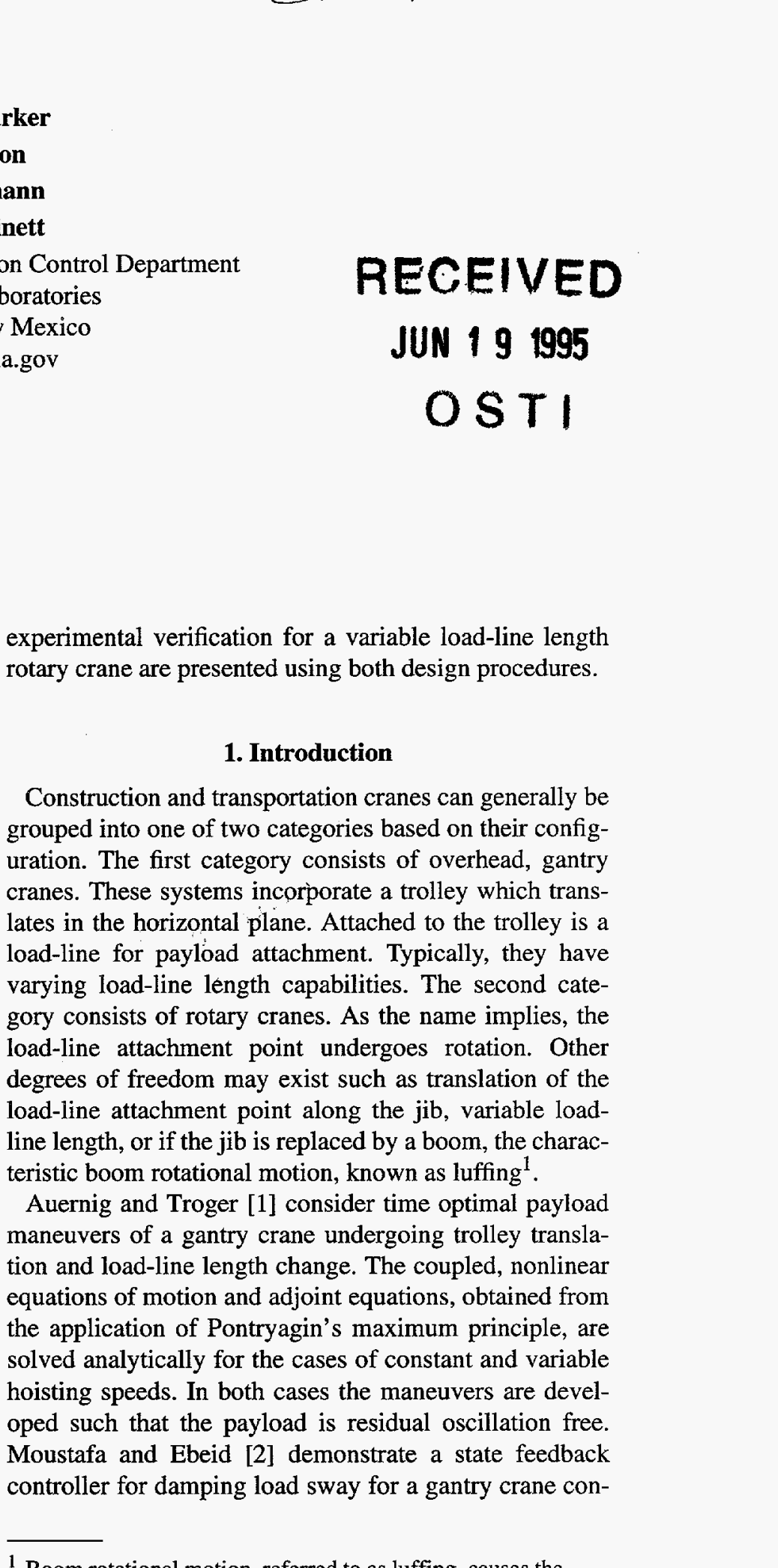

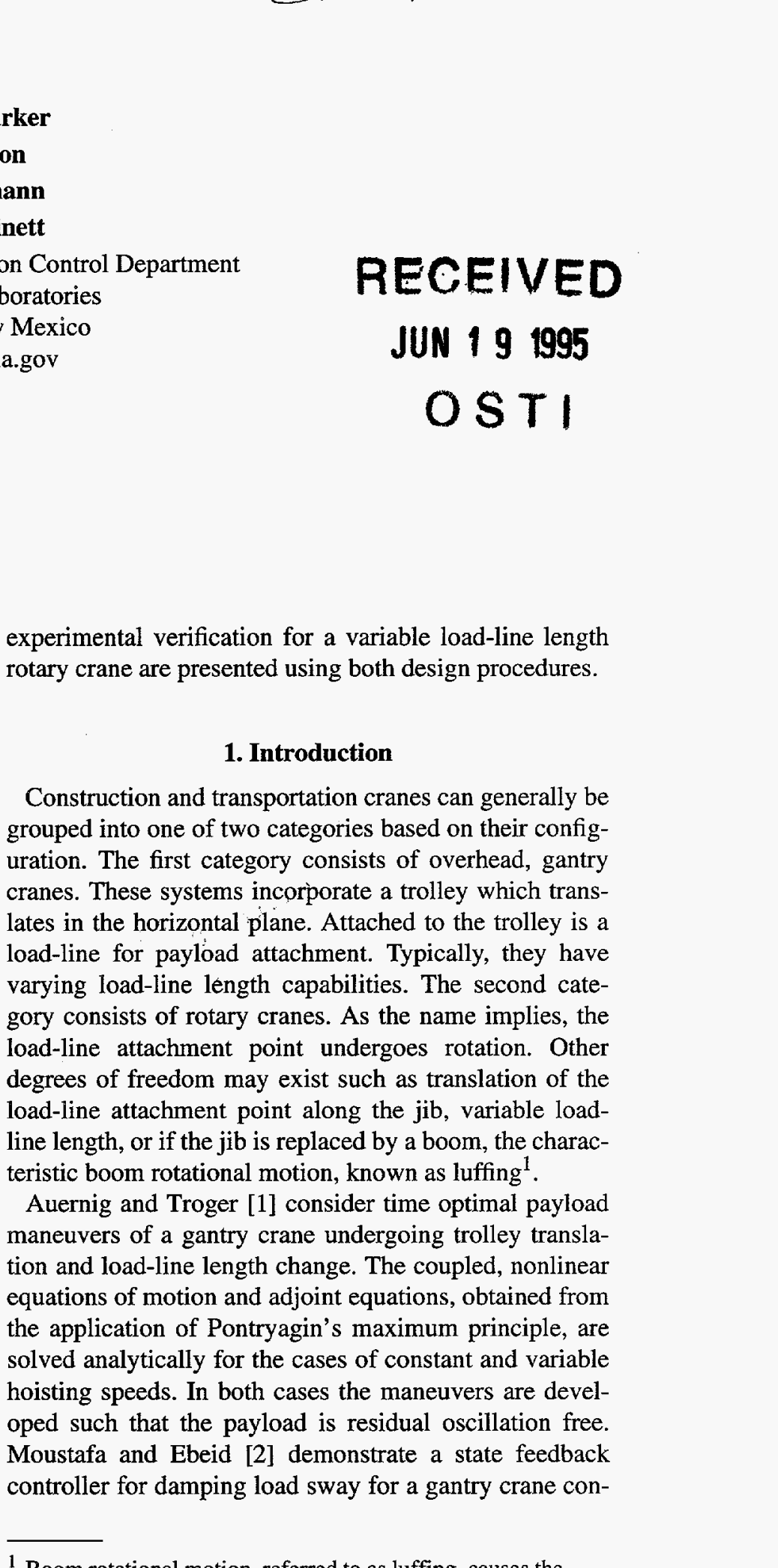

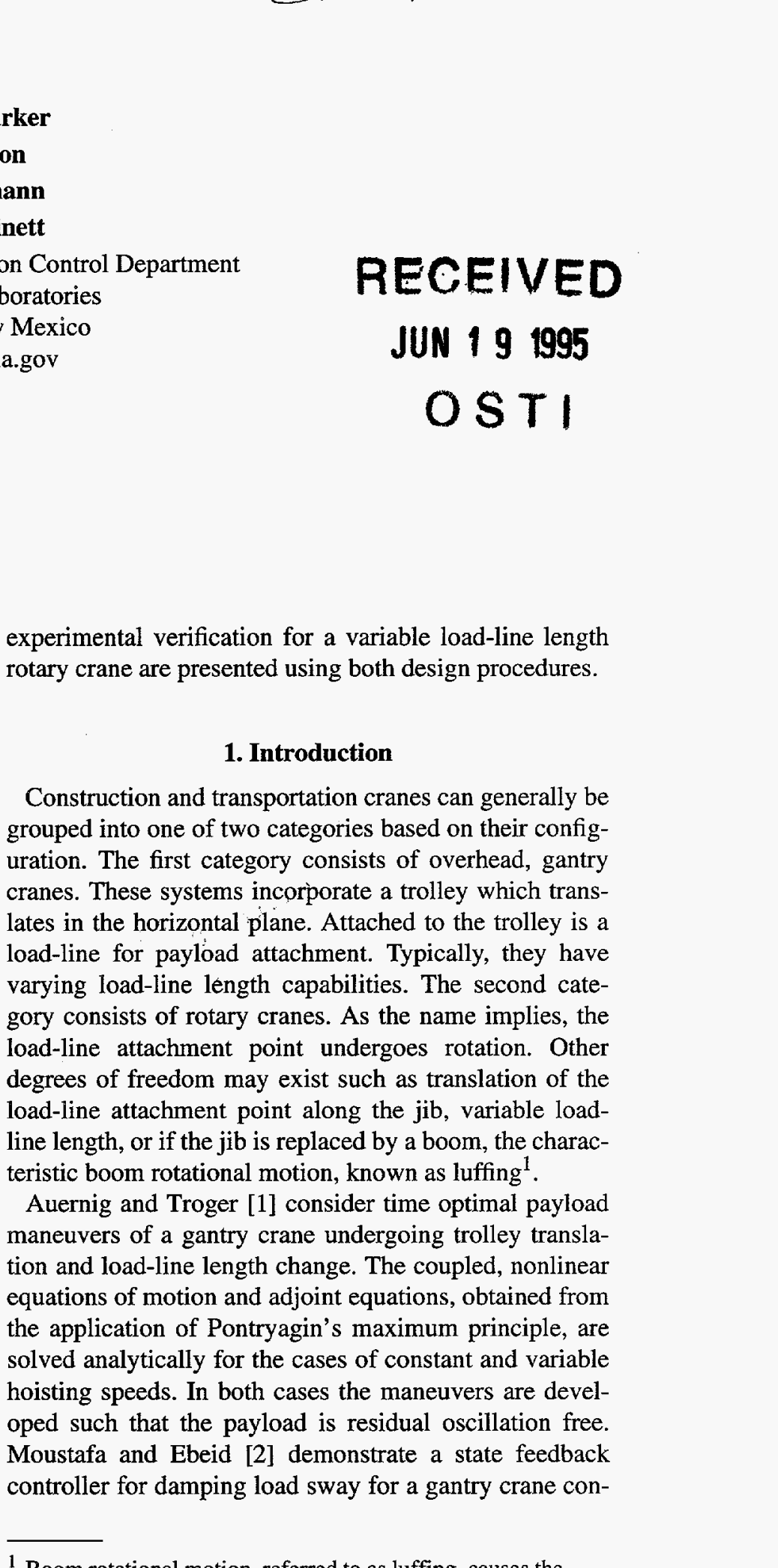

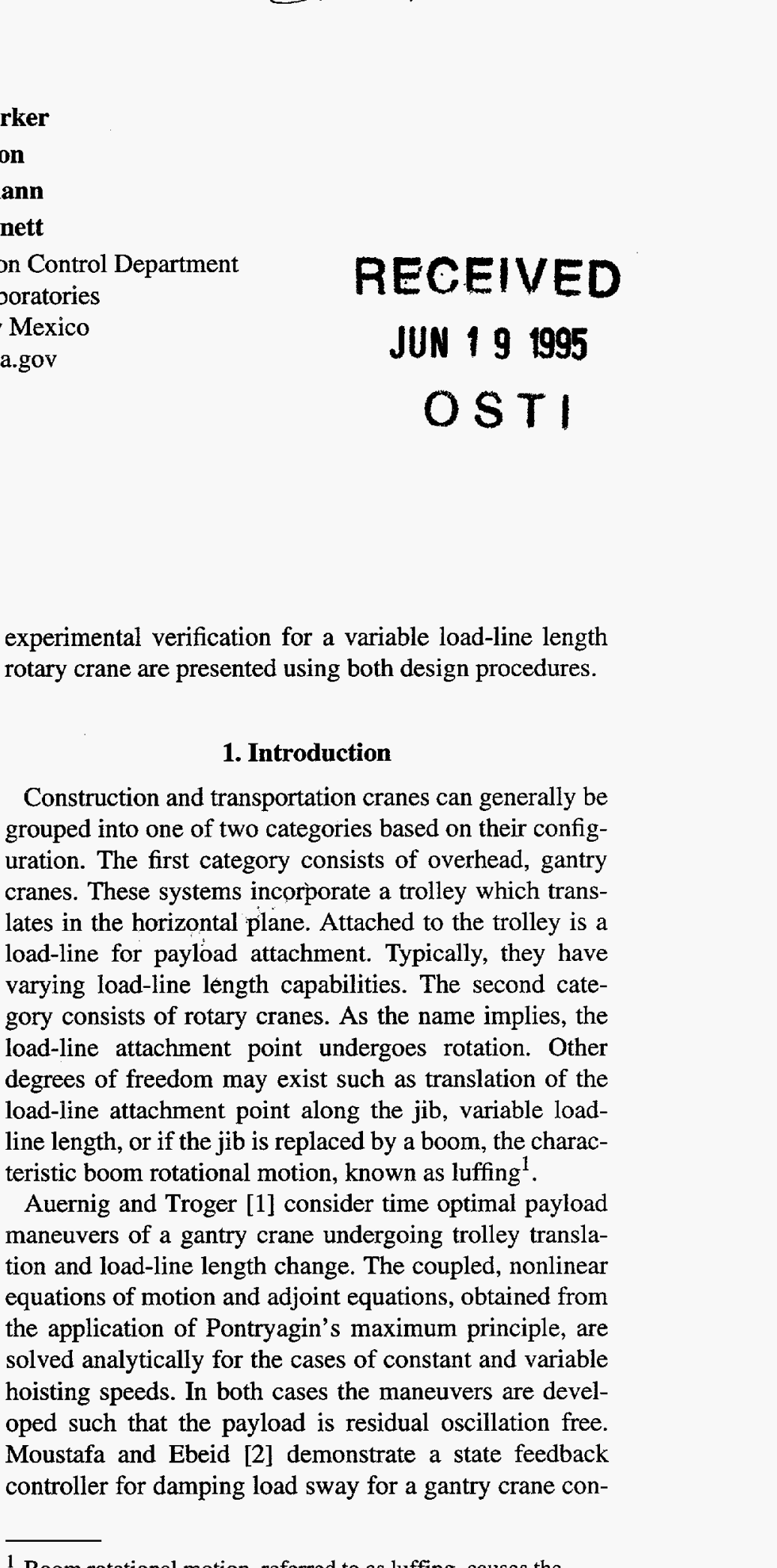

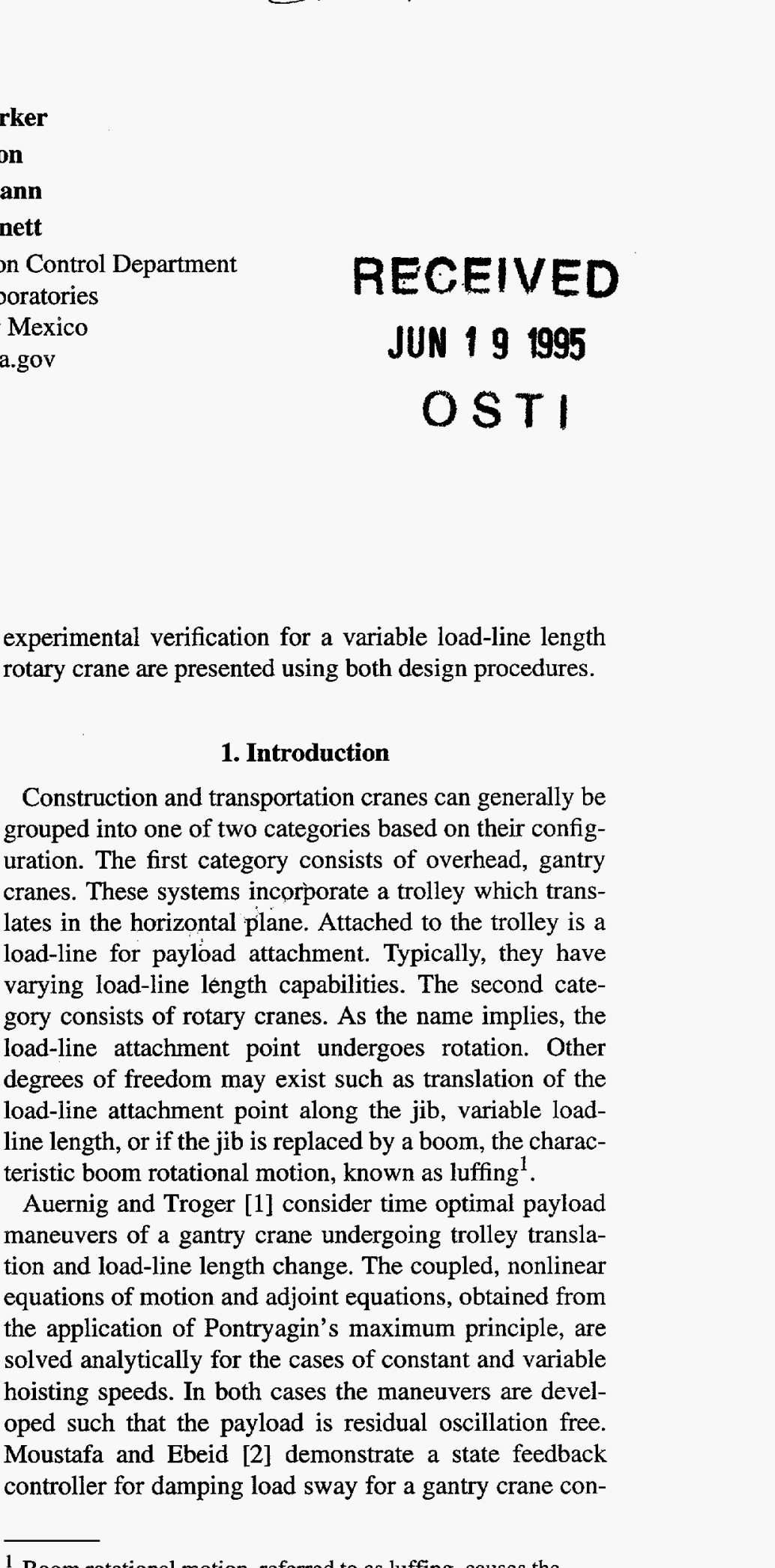

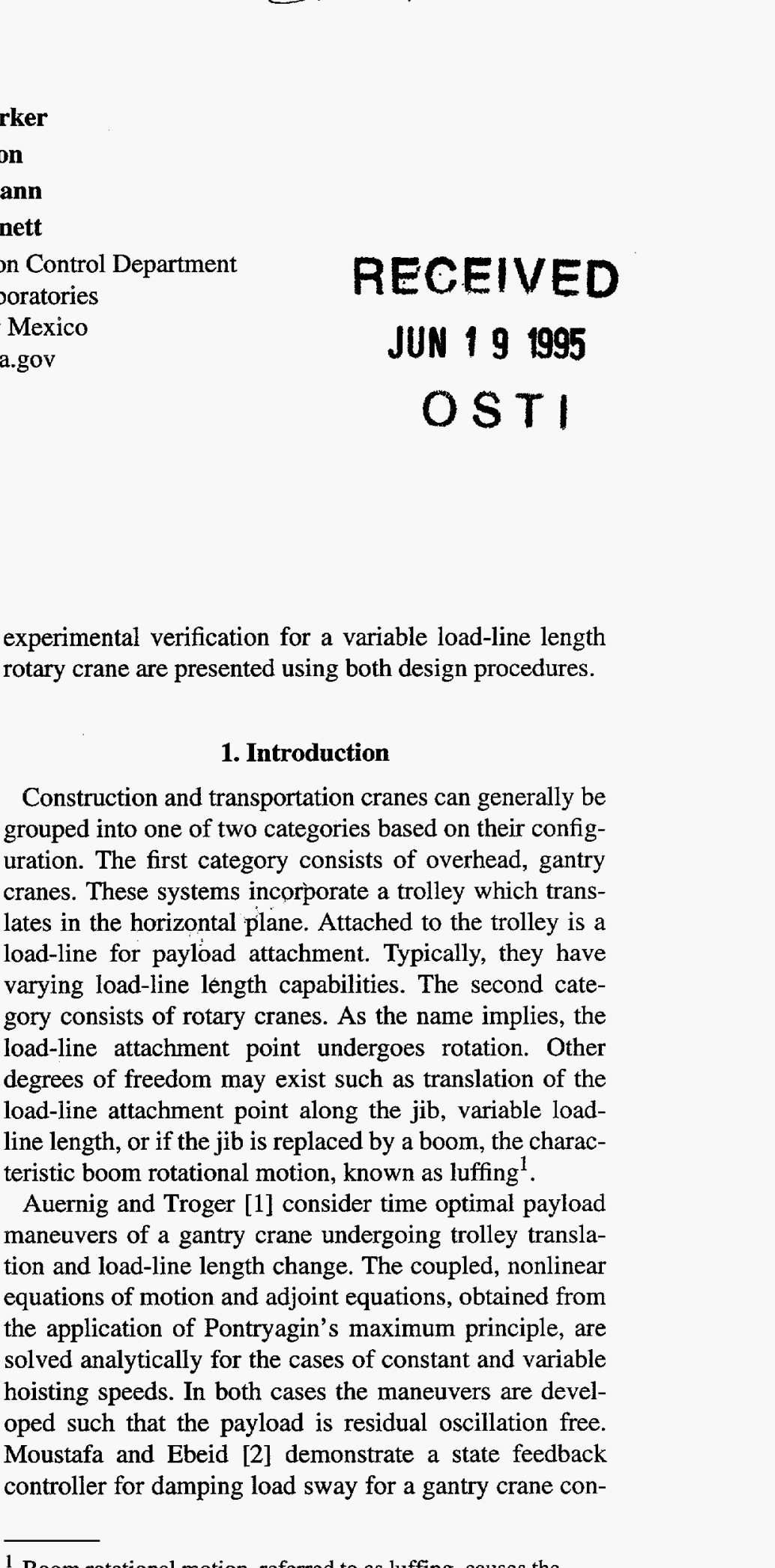

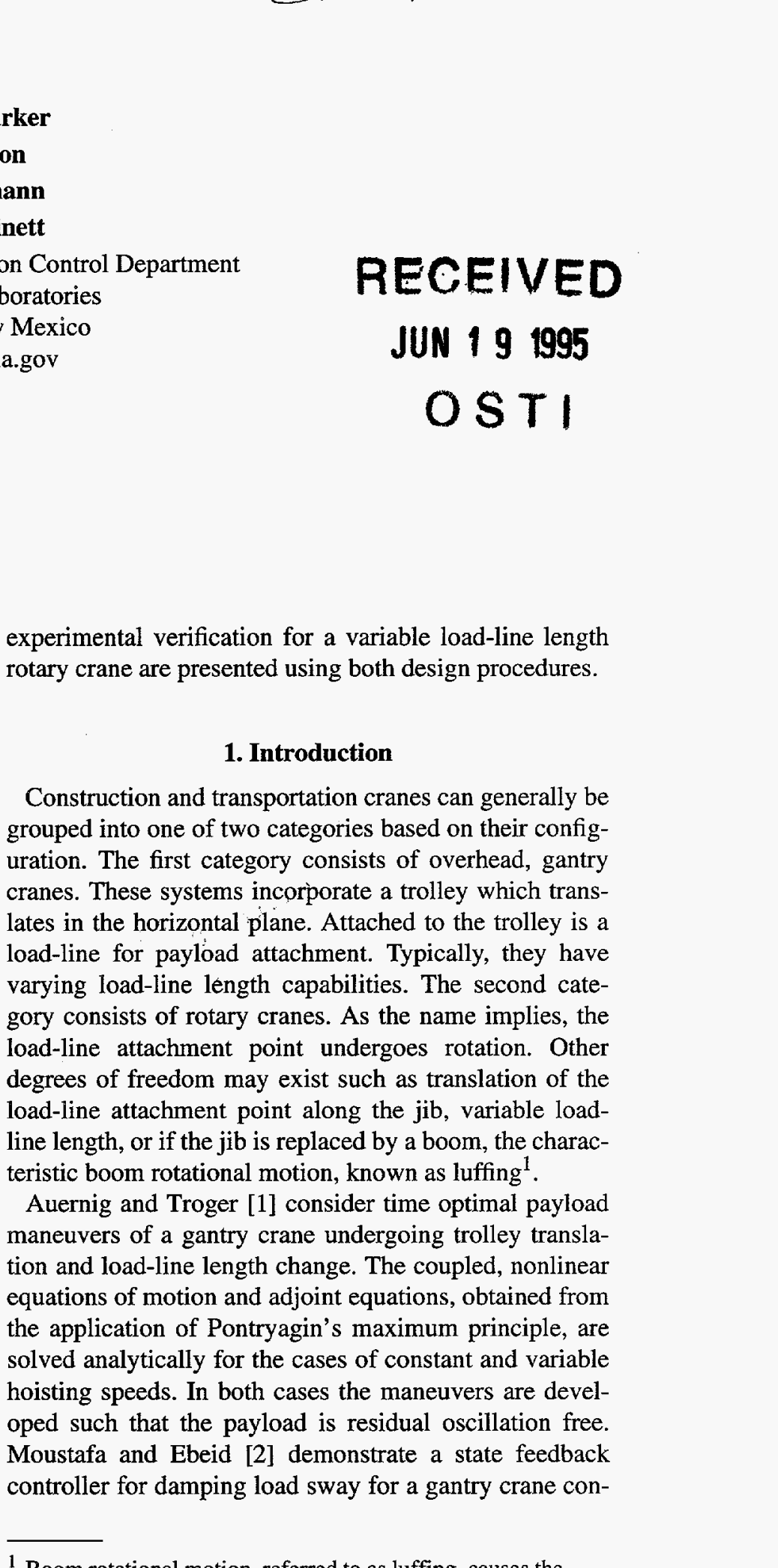

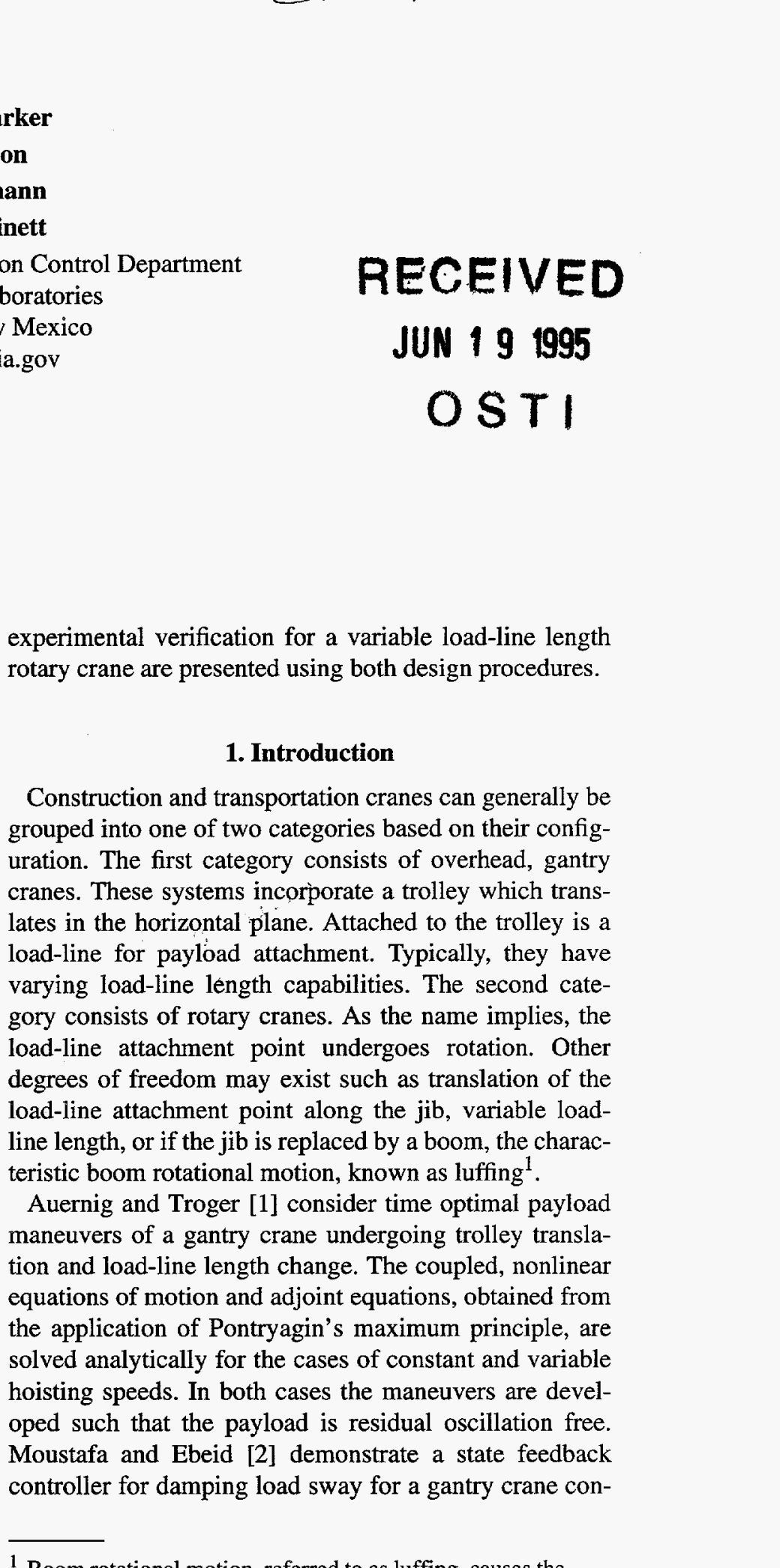

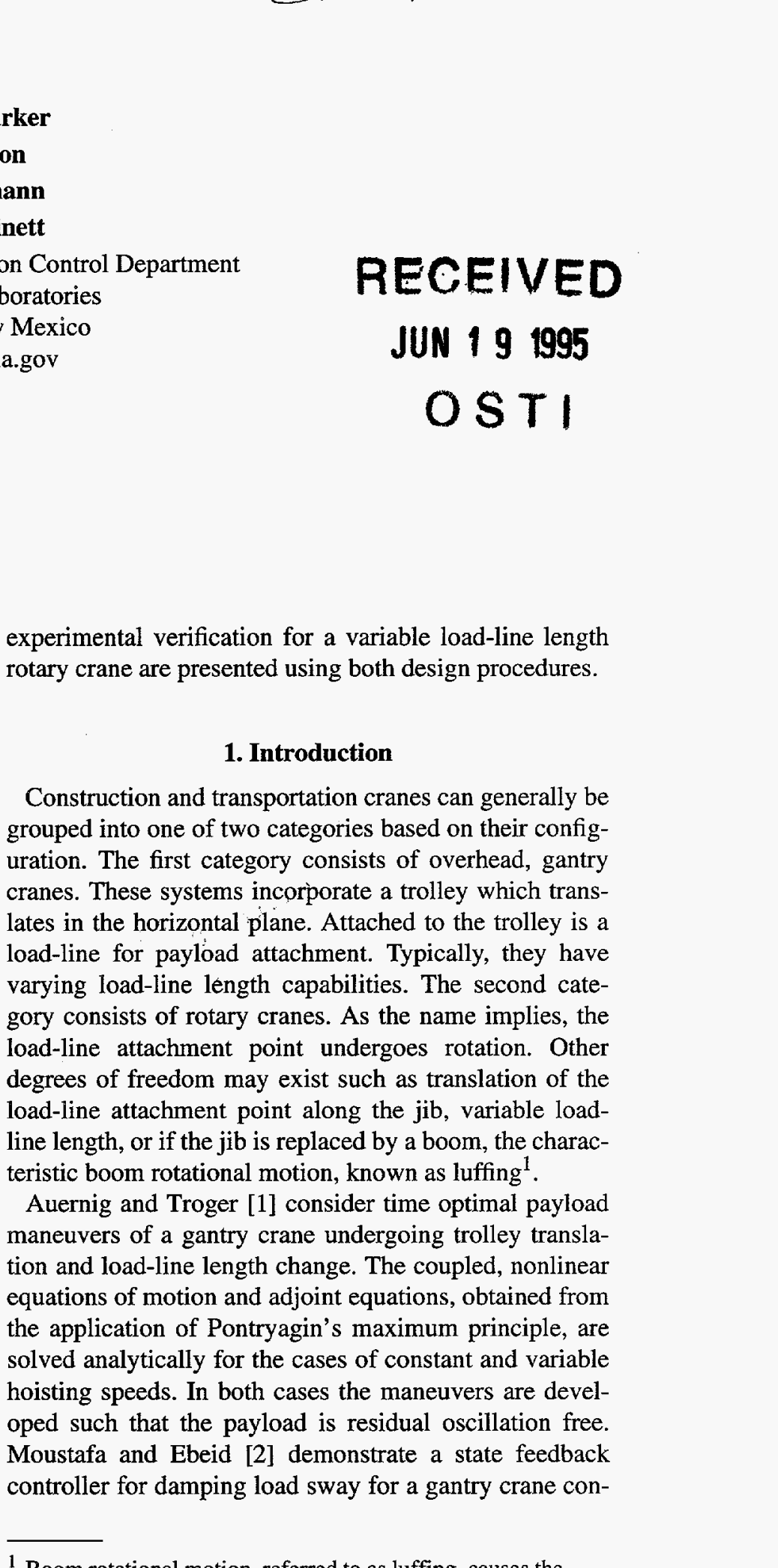

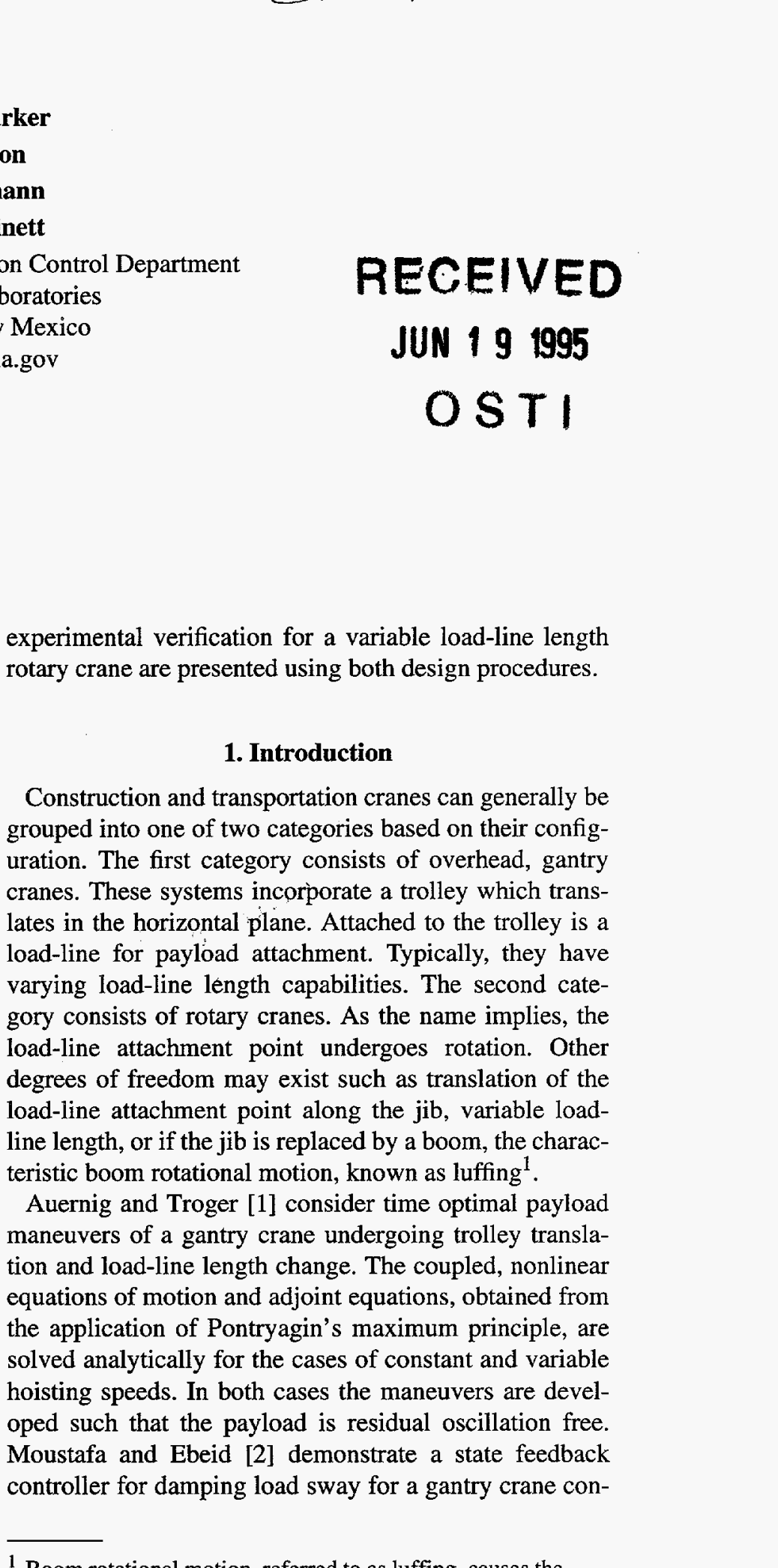

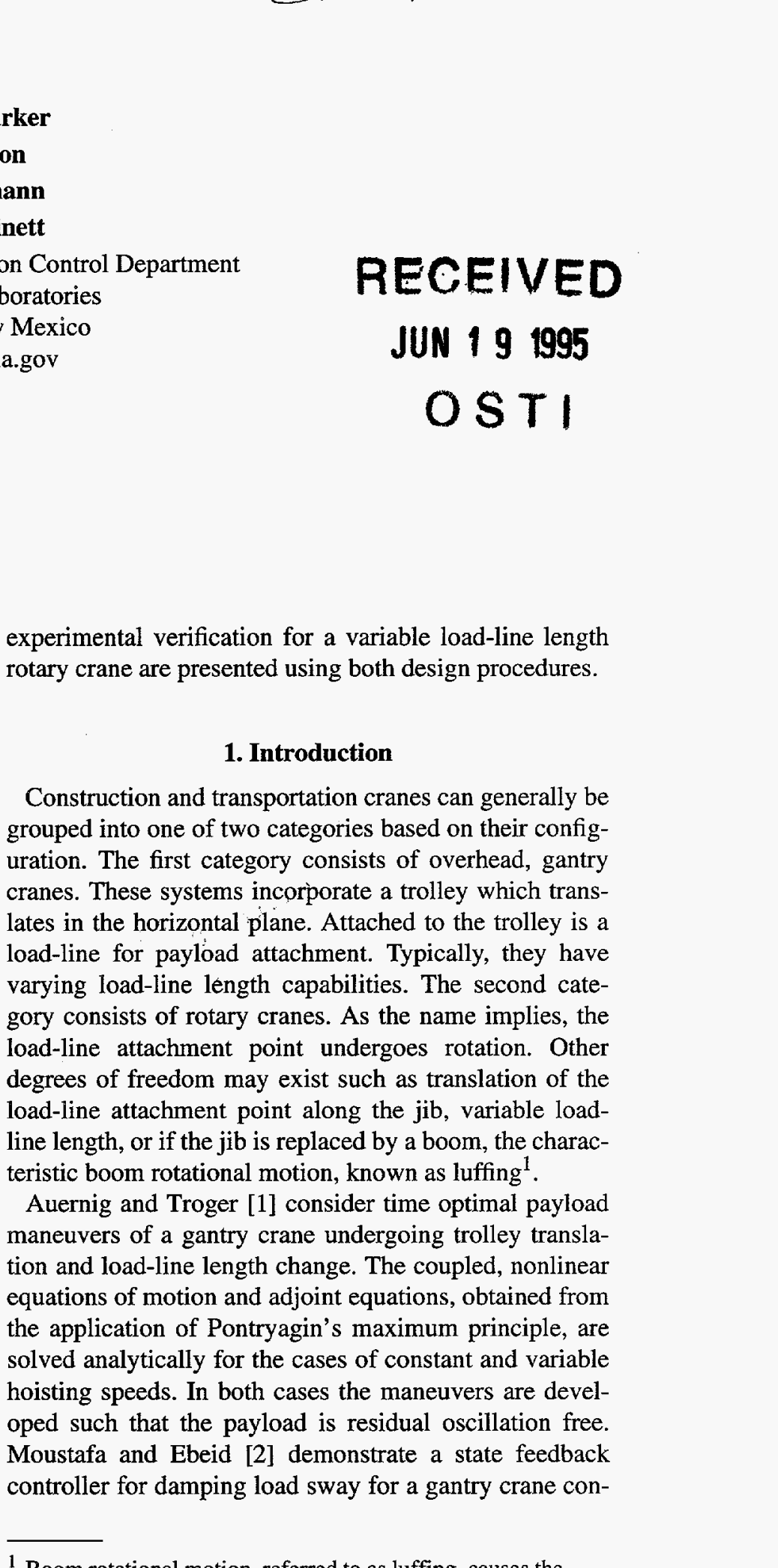

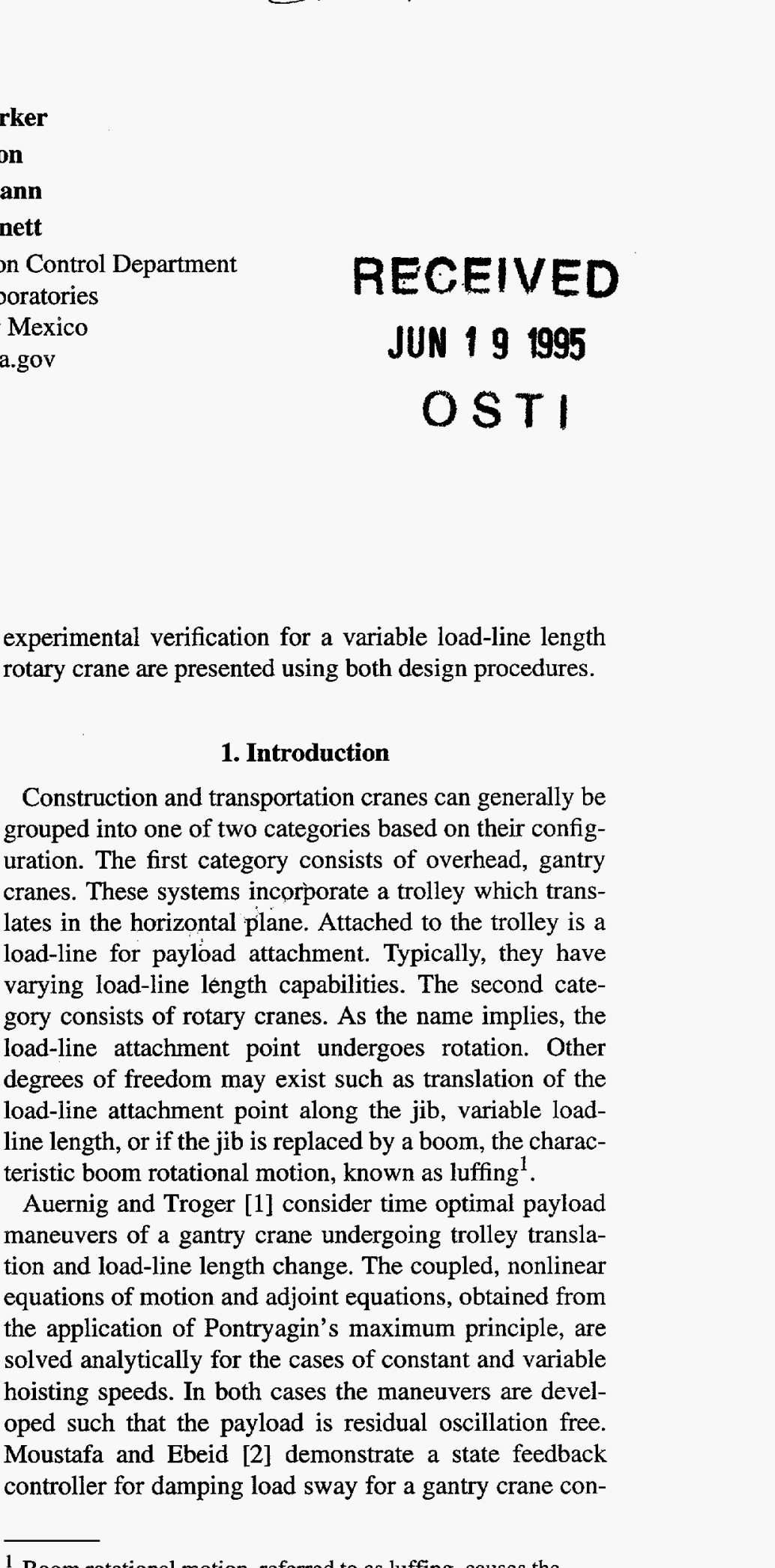

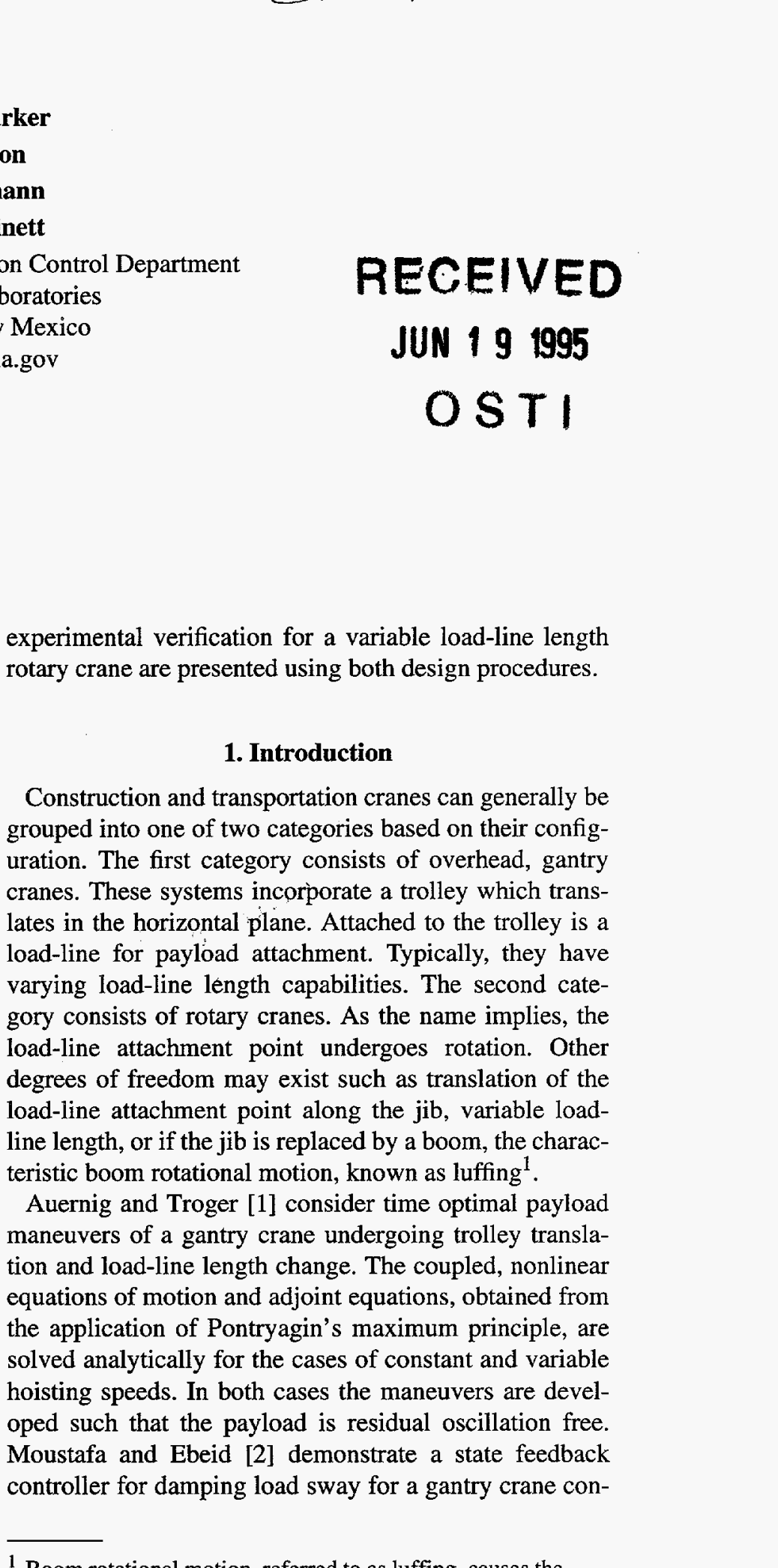

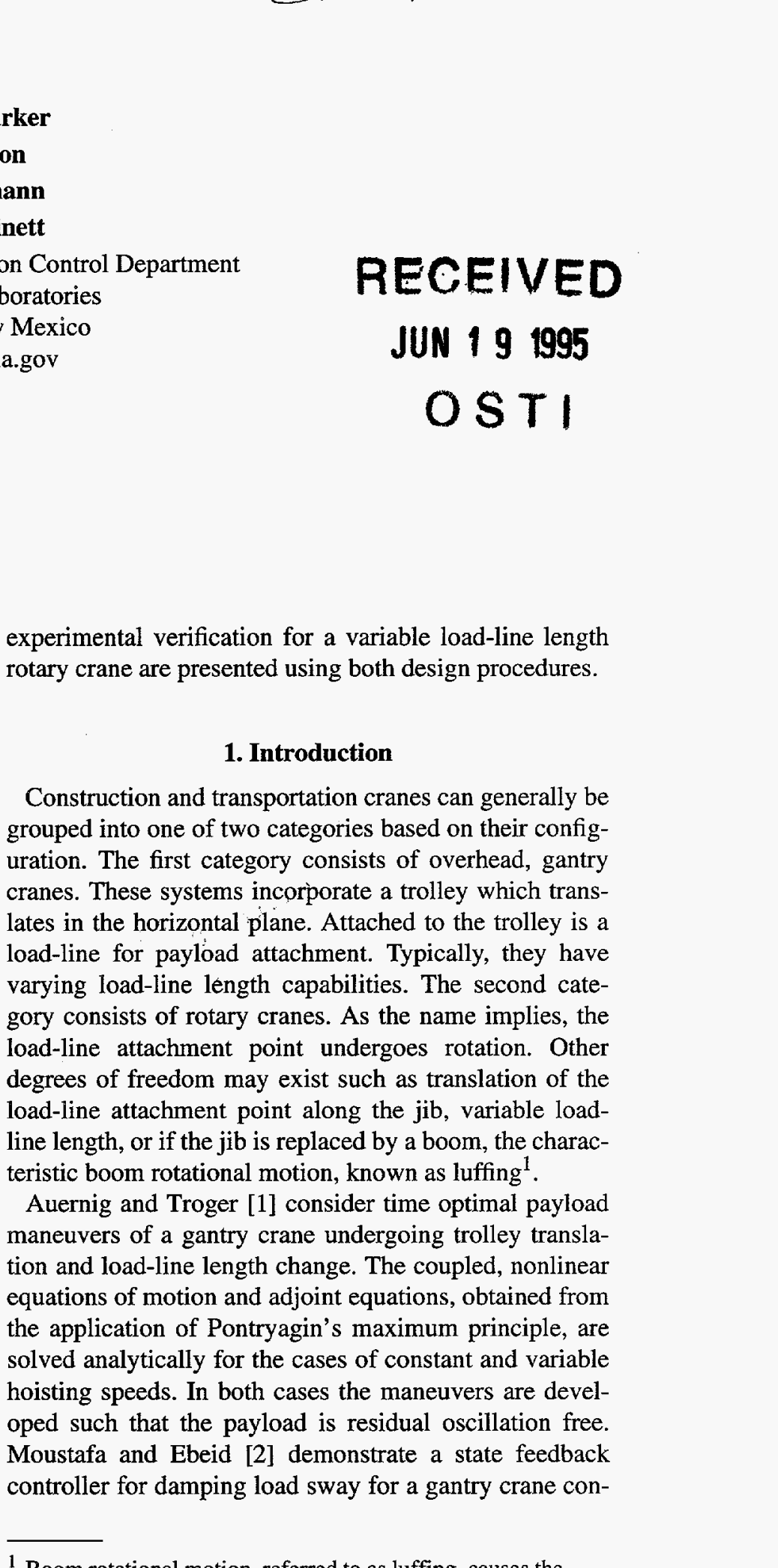

${ }^{1}$ Boom rotational motion, referred to as luffing, causes the tip of the boom to move vertically. 


\section{DISCLAIMER}

This report was prepared as an account of work sponsored by an agency of the United States Government. Neither the United States Government nor any agency thereof, nor any of their employees, makes any warranty, express or implied, or assumes any legal liability or responsibility for the accuracy, completeress, or usefulness of any information, apparatus, product, or process disclosed, or represents that its use would not infringe privately owned rights. Reference herein to any specific commercial product, process, or service by trade name, trademark, manufacturer, or otherwise does not necessarily constitute or imply its endorsement, recommendation, or favoring by the United States Government or any agency thereof. The views and opinions of authors expressed herein do not necessarily state or reflect those of the United States Government or any agency thereof. 


\section{DISCLAIMER}

Portions of this document may be illegible in electronic image products. Images are produced from the best available original document. 
figured to move along two orthogonal directions in the horizontal plane. This work is expanded on by Ebeid et. al. [3] to incorporate actuator dynamics into the crane model. Fliess et. al. [4] investigate a feedback linearizing controller for a one-dimensional gantry crane. Trolley traversal and load-line length changes are considered. Simulation results indicate the ability of the closed-loop controller to control load sway for relatively slow maneuvers. This same system is examined by Nguyen [5] where simulation and experimental results of a nonlinear statefeedback controller is used. Small motions are assumed about a specified operating point. This allows for decoupled equations of motion and decoupled controller design.

Sakawa and Nakazumi [6] investigate a rotary crane undergoing hub and boom rotation and load hoisting using a combined open and closed-loop approach. The open-loop input to the crane is designed based on a postulated set of functions such that the sway motion of the load is excited minimally. The closed-loop controller is then switched on when the maneuver is near the end, providing significant sway damping. Vaha et. al. [7] generate suboptimal, minimum time inputs for a rotary crane. Tracking is achieved via a state feedback control law. However, radial sway, due to centripetal acceleration of the payload, is not compensated. Souissi and Koivo [8] consider a rotary crane undergoing a boom-rotationboom maneuver using a proportional-integral-derivative controller similar to Fliess et.al. [4]. The simulation model considers both radial and tangential payload sway, however, the control strategy used results in residual load oscillation.

In this paper a procedure for input command shaping for a rotary jib crane with variable load-line length is introduced. The maneuver of interest is the residual oscillation free, point-to-point movement of a payload. The input angular acceleration to the jib motor is calculated by two methods. The first method uses a dynamic programming algorithm to obtain the general angular acceleration history. The second method uses a parameterized pulse acceleration profile. The initially unknown parameters are determined by solving a constrained optimization problem.

\section{Crane Description}

The crane considered here consists of a rotatable jib with a variable length load-line attached to the end. A mass, representing a payload, is attached to the end of the load-line. This apparatus is shown in Fig. 1

The $\hat{a}_{1}, \hat{a}_{2}, \hat{a}_{3}$ coordinate system is attached to the $\mathrm{jib}$ and rotates about the hub with angular rate $\dot{\gamma}$. The rotation angles $\theta_{1}, \theta_{2}$ are defined as rotations of the load-line about the $\hat{a}_{1}, \hat{a}_{2}$ axes respectively. The attachment point of the load-line to the jib is at a distance $x$ from the center of rotation of the hub. The load-line has time-varying

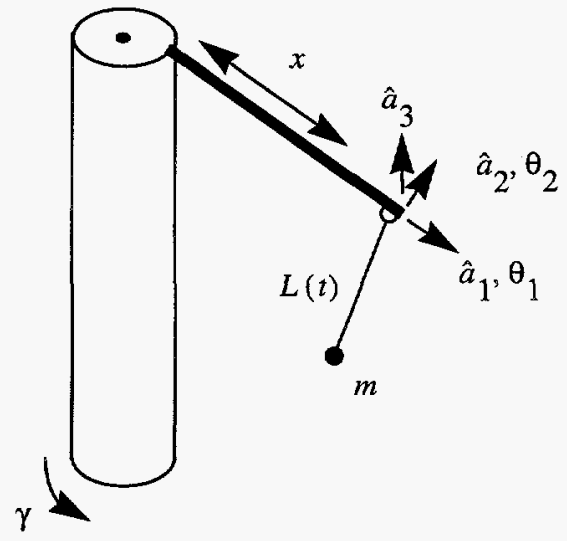

Figure 1. The Rotary Jib Crane.

length $L$ and the payload has mass $m$. The two rotations will from now on be referred to as the radial $\left(\theta_{2}\right)$ and the tangential $\left(\theta_{1}\right)$. The input to this system is the hub rotation trajectory $\gamma(t)$ and the outputs are the rotation angles of the load-line, $\theta_{1}(t), \theta_{2}(t)$.

The experimental system uses a constant acceleration, computer controlled, direct-drive, motor. Physical values for $x, m$ are given in Table 1 . The maneuver considered consists of a $90^{\circ} \mathrm{jib}$ rotation where at the end of the jib maneuver, the payload is oscillation free.

Table 1. Physical quantities used for the experimental apparatus.

\begin{tabular}{|c|c|c|}
\hline Parameter & Units & Value \\
\hline \hline$x$ & $m$ & 0.659 \\
\hline$m$ & $k g$ & 0.05 \\
\hline$L_{o}$ & $m$ & 1.02 \\
\hline$c_{1}$ & $m$ & 0.096 \\
\hline$c_{2}$ & $m$ & 0.096 \\
\hline
\end{tabular}

\section{Equations of Motion}

Using the rotating $\hat{a}_{1}, \hat{a}_{2}, \hat{a}_{3}$ coordinate system, the vector from the center of rotation of the hub to the payload is given by

$$
\begin{aligned}
\underline{p}(t)= & \left(x-L(t) \cos \left[\theta_{1}(t)\right] \sin \left[\theta_{2}(t)\right]\right) \hat{a}_{1}+ \\
& L(t) \sin \left[\theta_{1}(t)\right] \hat{a}_{2}- \\
& L(t) \cos \left[\theta_{1}(t)\right] \cos \left[\theta_{2}(t)\right] \hat{a}_{3}
\end{aligned}
$$

Lagrange's equations 


$$
\frac{d}{d t}\left(\frac{\partial \mathcal{L}}{\partial \dot{\theta}_{i}}\right)-\frac{\partial \mathcal{L}}{\partial \theta_{i}}=0
$$

are applied to this system where the Lagrangian $\mathcal{L}$

$$
\mathcal{L}=T-V
$$

is the difference between the kinetic energy $T$ and the potential energy $V$.

With the aid of Fig. 1 and Eq. 1, the kinetic and potential energy expressions can be found and when substituted into Eq. 2 yield the following equations of motion

$$
\left[\begin{array}{c}
\ddot{\theta}_{1} \\
\ddot{\theta}_{2}
\end{array}\right]+2\left[\begin{array}{cc}
\dot{L} & -\dot{\gamma} \\
\dot{L} & \frac{\dot{L}}{L}
\end{array}\right]\left[\begin{array}{l}
\dot{\theta}_{1} \\
\dot{\theta}_{2}
\end{array}\right]+\left[\begin{array}{cc}
\left(\frac{g}{L}-\dot{\gamma}^{2}\right) & -\left(\ddot{\gamma}+2 \dot{\gamma} \frac{\dot{L}}{L}\right) \\
\dot{\gamma}+2 \dot{\gamma} \frac{\dot{L}}{L} & \left(\frac{g}{L}-\dot{\gamma}^{2}\right)
\end{array}\right]\left[\begin{array}{c}
\theta_{1} \\
\theta_{2}
\end{array}\right]=-\frac{x}{L}\left[\begin{array}{c}
\ddot{\gamma} \\
\dot{\gamma}
\end{array}\right]
$$

where small angle assumptions have been exploited for $\theta_{1}, \theta_{2}$ and their derivatives.

The load-line length changes during the maneuver as a function of the hub rotation according to

$$
L=L_{o}-\sqrt{x^{2}+c_{1}^{2}+c_{2}^{2}+2 x c_{1} \cos \gamma+2 x c_{2} \sin \gamma}
$$

The values used for $L_{o}, c_{1}$, and $c_{2}$ are given in Table 1 . For these values, and a $90^{\circ}$ jib rotation, the load-line length has initial and final values of $0.26 \mathrm{~m}$. During the maneuver, the length decreases symmetrically, about the $45^{\circ}$ position, to a minimum length of $0.23 \mathrm{~m}$.

In the following, a numerical solution for the hub rotation $\gamma(t)$ yielding the residual oscillation free motion of the payload, is found relying on the equations of motion of Eq. 4.

\section{Maneuver Generation}

Two methods for hub angle generation are considered. The first uses a dynamic programming technique where the discretized hub motion is found by minimizing the hub motor effort while simultaneously enforcing the payload oscillation constraints. The second method uses a postulated hub motion which is parameterized by five values. These values are found by solving a parameter optimization problem which minimizes a cost function that penalizes the residual oscillation.

\subsection{Dynamic Programming Approach}

The dynamic programming optimal control problem for obtaining the hub trajectory $\gamma(t)$ is

$$
\text { MINIMIZE: } \quad J=\int_{0}^{t_{f}} \ddot{\gamma}^{2} d t
$$

SUBJECT TO: $\quad$ Eq. 4

CONSTRAINED BY:

$$
\begin{aligned}
& \theta_{1}\left(t_{f}\right)=\dot{\theta}_{1}\left(t_{f}\right)=\theta_{2}\left(t_{f}\right)=\dot{\theta}_{2}\left(t_{f}\right)=0 \\
& \gamma\left(t_{f}\right)=90^{\circ}, \dot{\gamma}\left(t_{f}\right)=0 \\
& t_{f}=2.2
\end{aligned}
$$

The implementation of the dynamic programming solution method utilizes a discretization of the hub angular acceleration into 100 zero order hold values, i.e., the input is allowed to change every 0.022 seconds during the maneuver and the dynamic programming algorithm will return the optimal value for each discretized point.

As stated by Dohrmann [9] [10], the dynamic programming method is well suited to input command shaping applications since each iteration requires order $M$ calculations where $M$ is the number of discretizations. In contrast, gradient based sequential quadratic programming methods require order $M^{3}$ calculations per iteration.

\subsection{Parameter Optimization Approach}

The use of this method is motivated by the hardware restrictions of requiring constant acceleration commands for the hub. However, this method illustrates that suboptimal trajectories, in terms of hub motor effort, exist satisfying the primary objective of residual oscillation free motion.

The hub angular acceleration profile is postulated using the pulse-coast-pulse form shown below The hub motion is uniquely described by the five parameters $A_{1}$ the first pulse magnitude, $T_{1}$ the first pulse duration, $T_{2}$ the coast time, $A_{2}$ the second pulse magnitude, and $T_{3}$ the second pulse duration.

The parameter optimization problem for obtaining the hub trajectory $\gamma(t)$ is

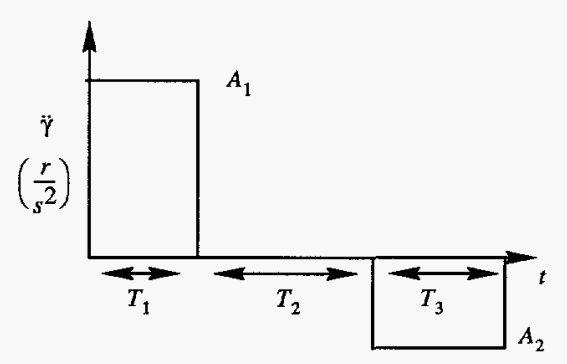

Figure 2. Postulated Angular Acceleration Profile 
Minimize: $\quad J=\int_{t_{f}}^{t_{f}+\Delta}\left(\theta_{1}^{2}+\theta_{2}^{2}\right) d t$

SubJeCt To: $\quad$ Eq. 4

CONSTRAINED BY:

$$
\begin{aligned}
& \dot{\theta}_{1}\left(t_{f}\right)=\dot{\theta}_{2}\left(t_{f}\right)=0 \\
& \gamma\left(t_{f}\right)=90^{\circ}, \dot{\gamma}\left(t_{f}\right)=0 \\
& t_{f}=\text { Free }
\end{aligned}
$$

In this case the cost function is a measure of the residual oscillation of the payload. A fundamental difference between this approach and the dynamic programming method is that the final time is free. The quantity $\Delta$ was chosen as 2.0 seconds, to capture residual oscilation in the cost function.

\section{Results}

\subsection{Simulation}

Using the values of Table 1, the trajectory features for residual oscillation free motion using both dynamic programming and parameter optimization are shown in Figure 3 through Figure 6 . The values for the parameter optimization method are shown in Table 2 where a recursive quadratic programming [11] method is employed. The initial guess for the parameter optimization method was chosen based on an approximation of the dynamic programming solution to a pulse profile. The resulting maneuver completed in 2.1 seconds compared to the dynamic programming maneuver duration of $2.0 \mathrm{sec}-$ onds.

Table 2. Values of Optimal Hub Acceleration Pulse Profile Parameters.

\begin{tabular}{|c|c|c|}
\hline Parameter & Units & Value \\
\hline \hline$A_{1}$ & $r / s^{2}$ & 1.346 \\
\hline$T_{1}$ & $s$ & 0.903 \\
\hline$T_{2}$ & $s$ & 0.390 \\
\hline$A_{2}$ & $r / s^{2}$ & 1.346 \\
\hline$T_{3}$ & $s$ & 0.903 \\
\hline
\end{tabular}

\subsection{Experimental}

As mentioned previously, the experimental hardware requires constant acceleration hub commands, excluding the use of the dynamic programming results for verification. The hub trajectory of the parameter optimization results, however, is implemented on the hardware. The resulting motion is observed to be residual oscillation free with no modification to the optimized solution. This implies excellent ability to model and simulate the physi- cal system using Eq. 4. Because of the correlation between simulation and experimental results, the simulation plots are used in lieu of measured experimental data.

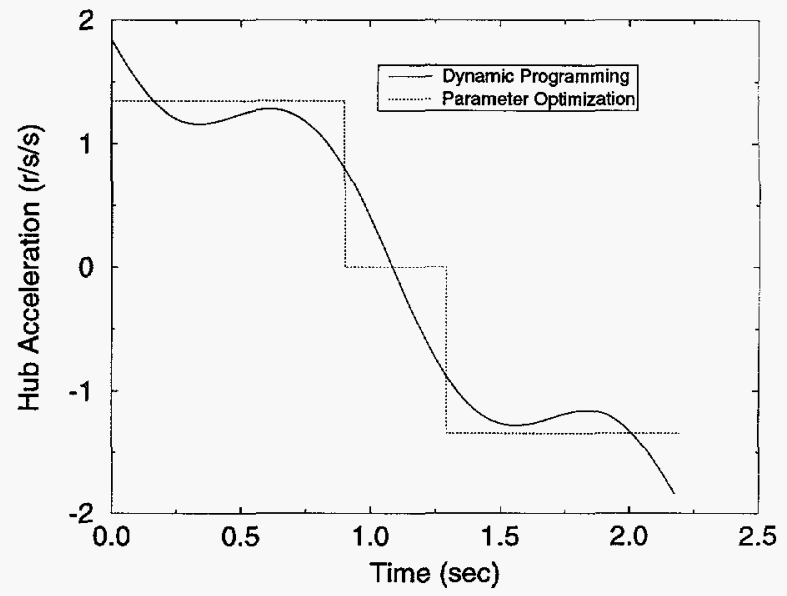

Figure 3. Hub Acceleration -- Dynamic Programming vs. Parameter Optimization.

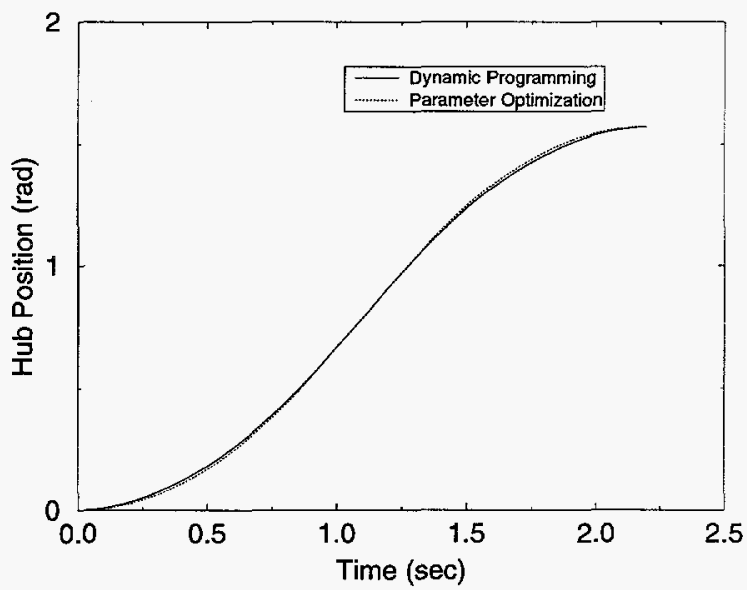

Figure 4. Hub Position -- Dynamic Programming vs. Parameter Optimization.

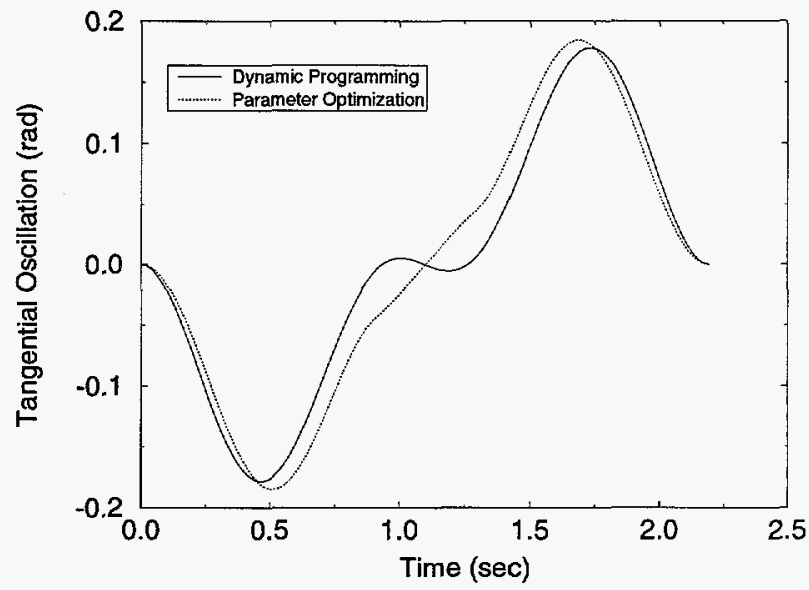

Figure 5. Tangential Oscillation $\theta_{1}$-- Dynamic Programming vs. Parameter Optimization. 


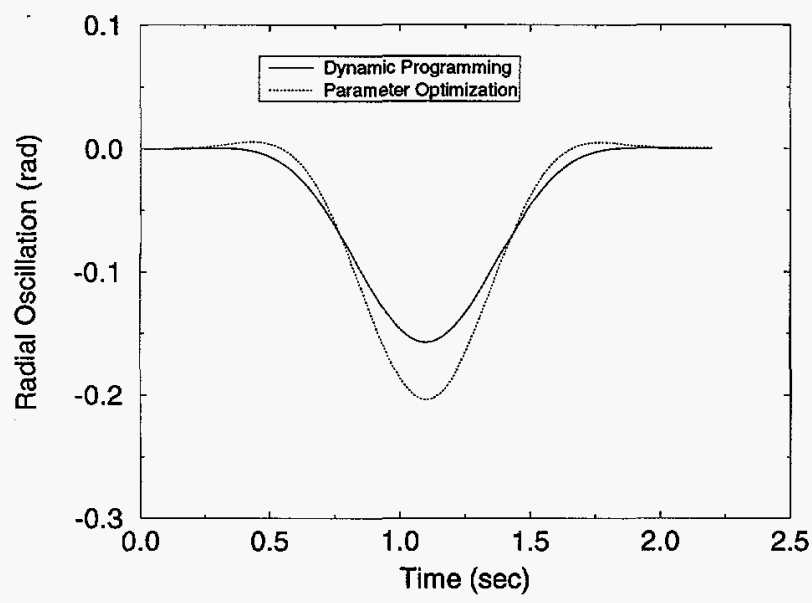

Figure 6. Radial Oscillation $\theta_{2}$-- Dynamic Programming vs. Parameter Optimization.

\section{Summary}

A dynamic programming method was employed for obtaining the hub angular acceleration history for a variable load-line jib crane producing residual oscillation free payload motion. It was shown that the hub angular acceleration could also be postulated using a bang-coast-bang shape to achieve the desired residual oscillation free behavior. The parameters of this shape were calculated using a recursive quadratic programming numerical optimization code. The time required for a solution of this gradient based approach was dependent on the quality of the initial guess. When the guess was based on an approximation to the results of the dynamic programming approach, the time required for solution was approximately the same as the dynamic programming method. It should be noted, however, that the dynamic programming method requires no initial guess. This feature is particularly useful for systems with time-varying or nonlinear equations of motion where physical insight into the solution is elusive.

The parameter optimization results were verified experimentally using constant acceleration commands to the hub motor. The resulting residual oscillation free motion of the payload was achieved with no "tuning" of the crane simulation indicating the ability to accurately model the system.

\section{Acknowledgments}

This work performed at Sandia National Laboratories is supported by the U.S. Department of Energy under contract DE-AC0494AL85000.

\section{References}

1. J.W. Auernig and H. Troger, "Time Optimal Control of Overhead Cranes with Hoisting of the Load," Automatica, Vol. 23, No. 4, pp. 437-447, 1987.
2. K.A.F. Moustafa and A.M. Ebeid, "Nonlinear Modeling and Control of Overhead Crane Load Sway," Journal of Dynamic Systems, Measurement, and Control, Vol. 110, pp. 266-271, 1988.

3. A.M. Ebeid, K.A.F. Moustafa and H.E. EmaraShabaik, "Electromechanical Modelling of Overhead Cranes," International Journal of Systems Science, Vol. 23, No. 12, pp. 2155-2169, 1992.

4. M. Fliess, J. Levine P. Rouchon, "A Simplified Approach of Crane Control via a Generalized StateSpace Model," IEEE Proceedings of the 30th Conference on Decision and Control, Brighton, England, pp. 736-741, 1991.

5. H.T. Nguyen, "State-Variable Feedback Controller for an Overhead Crane," Journal of Electrical and Electronics Engineering, Australia, Vol. 14, No. 2, pp. 75-84, 1994.

6. Y. Sakawa and A. Nakazumi, "Modeling and Control of a Rotary Crane," Journal of Dynamic Systems, Measurement, and Control, Vol. 107, pp. 200-206, 1985.

7. P. Vaha, S. Pieska and E. Timonen, "Robotization of an Offshore Container Crane," Robots: Coming of Age, Proceedings of the 19th ISIR International Symposium, pp. 637-648, 1988.

8. R. Souissi and A.J. Koivo, "Modeling and Control of a Rotary Crane for Swing-Free Transport of Payloads," The First IEEE Conference on Control Applications, Dayton, OH, pp. 782-787, 1992.

9. C. R. Dohrmann and R. D. Robinett, "Input Shaping for Three-Dimensional Slew Maneuvers of a Precision Pointing Flexible Spacecraft," Proceedings of the American Control Conference, Baltimore, MD, pp. 2543-2547, 1994.

10. C. R. Dohrmann and R. D. Robinett, "Robot Trajectory Planning via Dynamic Programming,", Proceedings of the Fifth International Symposium on robotics and Manufacturing: Research, Education, and Applications, Maui, HI, pp. 75-81, 1994.

11. M. J. Hopper, Harwell Subroutine Library, AERER9185, UKAEA, Harwell, Oxon., UK, 1978. 